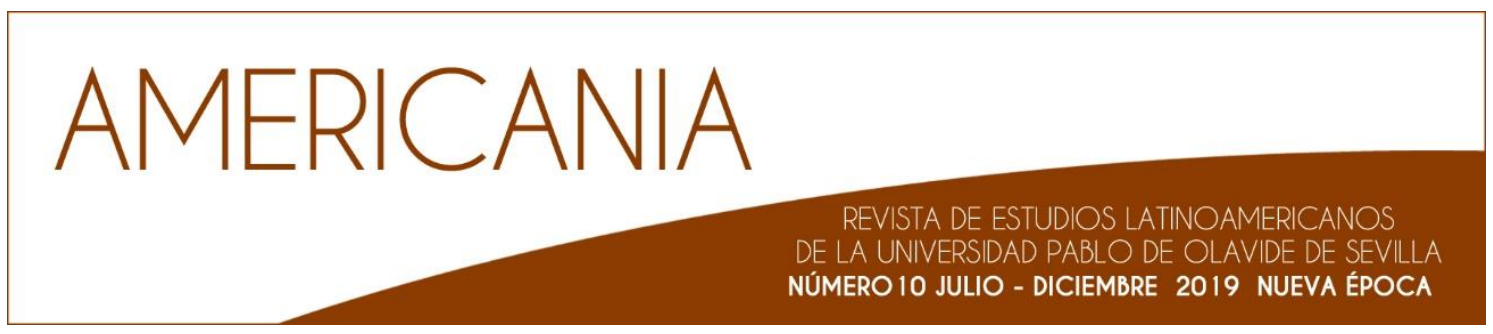

\title{
POLÍTICA DOMINICANA PARA ATRAER INMIGRACIÓN EUROPEA
}

$(1870-1950)$

jarvisluis@hotmail.com

Rafael Jarvis Luis ${ }^{1}$

Pontificia Universidad Católica Madre y Maestra

\section{Resumen}

Quienes dirigieron el Estado dominicano entre 1870 y 1950 desarrollaron políticas enfocadas a atraer inmigrantes europeos hacia la República Dominicana, con el doble propósito de aumentar el número de habitantes para incrementar la densidad de población y contribuir al progreso socioeconómico, mediante la presencia de trabajadores extranjeros. Diversas tácticas fueron aplicadas a fin de alcanzar este propósito. En el presente ensayo se describe el proceso que transita desde la promoción de la inmigración europea hacia el control de la inmigración afrodescendiente procedente de otras islas del Caribe.

\section{Palabras Clave}

Inmigración - Progreso - Leyes - Resoluciones - Legislación - Impuestos o tributos

1 Rafael Jarvis Luis es doctorado en Historia y Estudios Humanísticos: Europa, América, Arte y Lenguas, Universidad Pablo de Olavide de Sevilla. Profesor de Historia Dominicana en la Pontificia Universidad Católica Madre y Maestra. Miembro Correspondiente de la Academia Dominicana de la Historia. Autor de una investigación de mayor referencia sobre el pueblo de La Romana. Ha publicado varios trabajos de Historia en diversos medios. Pertenece al consejo académico de una prestigiosa revista de Historia en la República Dominicana. Intervino en diversos eventos científicos sobre temas históricos. Profesor invitado en la universidad Uninorte, Colombia. 


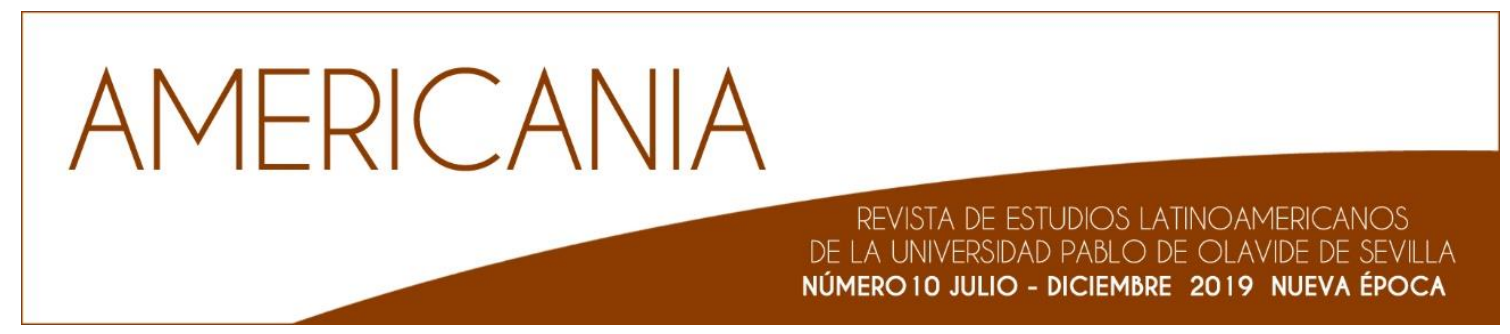

\title{
DOMINICAN POLICY TO ATTRACT EUROPEAN IMMIGRATION
}

(1870-1950)

\begin{abstract}
Those who led the Dominican State between 1870 and 1950 developed policies focused on attracting European immigrants to the Dominican Republic, with the dual purpose of increasing the number of inhabitants in order to increase population density and contributing to socioeconomic progress through the presence of foreign workers. Various tactics were applied in order to achieve this purpose. This essay describes the process, which goes from promoting European immigration to controlling Afro-descendant immigration from other islands in the Caribbean.
\end{abstract}

\section{Key Words}

Immigration - Progress - Laws - Resolutions - Legislation - Taxes 


\section{Introducción}

Se intentará responder en este artículo por qué en la República Dominicana, durante los años estudiados, se promovía el ingreso de inmigrantes europeos y por qué posteriormente se pretendió controlar la entrada y permanencia de inmigrantes procedentes del Caribe. Para entonces, la economía nacional se fundamentaba en actividades agroexportadoras, sobresaliendo la producción de miel de abejas, la tala de árboles de madera preciosa, la crianza de ganado, la siembra de tabaco, cacao, café y, posteriormente, la fabricación del azúcar de caña. Los productos tenían como destino, en un primer momento, los mercados europeos y, posteriormente, los Estados Unidos de Norteamérica. En aquella época se extendía el método de producción impulsado por la Revolución Industrial y los adelantos técnicos que la acompañaron; por lo tanto, era una aspiración de los gobernantes introducir estos avances como manifestación del progreso material al que aspiraban.

Para fundamentar la conveniencia de atraer inmigrantes al país, las autoridades dominicanas consideraron dos aspectos: por un lado, la necesidad de elevar el número de habitantes de la República Dominicana, a fin de saldar la desventaja numérica respecto la población de Haití, nación vecina de la cual se había separado el 27 de febrero de 18442; y, por el otro, la necesidad de impulsar el desarrollo y progreso del país mediante el aporte de ciudadanos emprendedores que trajeran experiencias y conocimientos adquiridos en los países europeos más avanzados.

En Europa, de manera paradójica, el progreso, la revolución industrial y la explosión demográfica de los grandes núcleos urbanos convivían con el hambre, la miseria y el éxodo de sus habitantes hacia América en busca del bienestar que faltaba en sus lugares de origen. Los países que los ciudadanos españoles, italianos, irlandeses, escoceses y alemanes elegían como destino para migrar eran los Estados Unidos, Argentina, Brasil y Cuba3 . En la Argentina se asentaron miles de trabajadores europeos que se desempeñaron como agricultores, mecánicos, herreros, cocineros, músicos, entre otros; en conjunto, lograron impulsar la economía argentina con su

2 Conforme a las informaciones de la época, la República Dominicana tenía 400.000 habitantes y Haití 800.000. Gobierno Dominicano. Atlas de Ch. Bouret, París, 1889, en H. Thomasset. "Informe dirigido al señor Ministro de Fomento y Obras Públicas". Santo Domingo, Gaceta Oficial, año XVIII, 17 de enero de 1891, Biblioteca Nacional Pedro Henríquez Ureña, en adelante BNPHU, No. 856.

3 Naranjo Orovio, Consuelo, Las migraciones de España a Iberoamérica desde la independencia, Catarata-CSIC, Madrid, 2010. 
trabajo. Por ello, las autoridades dominicanas anhelaron replicar aquella experiencia promoviendo condiciones favorables para quienes desearan salir de Europa con destino a esta isla del Caribe.

Por otra parte, muchos de los afrodescendientes que habitaban las colonias británicas del Caribe, luego de abolirse la esclavitud, se vieron en la necesidad de salir en un forzado éxodo hacia otras islas cercanas en busca de espacio para subsistir porque, en sus lugares de origen, un arbitrario régimen de propiedad de la tierra les impedía el acceso a ese medio de capital. Ellos, lvego de ser declarados libres, permanecieron como asalariados en las plantaciones donde fueron esclavos a cambio de pagos exiguos; también quedaron excluidos del acceso a cargos públicos y de la posibilidad de ser electos en las asambleas que decidían su destino económico. Esta situación llevó al antropólogo Mintz a afirmar que la emancipación en el Caribe, con excepción de Haití, no alteró en lo más mínimo la estructura de poder precedente4. Debido al alto número de libertos sin tierra en las colonias caribeñas del Reino Unido, las autoridades británicas del Colonial Office incentivaron la salida de sus súbditos desde Barbados, Saint Kitts, Nevis, Montserrat, Antigua, Jamaica, Islas Vírgenes, Dominica, Trinidad \& Tobago, Granada y San Vicente 5 hacia diversas partes del continente americano. La República Dominicana fue uno de aquellos destinos 6 .

\section{Migración e idea de progreso}

En la República Dominicana, a lo largo de los años que abarca este estudio, se puso de manifiesto el interés por atraer la inmigración europea con el propósito de impulsar el progreso. Sucesivas administraciones gubernamentales coincidieron en este objetivo. En la administración de monseñor Fernando Arturo de Meriño, el ministro Eliseo Grullón expresaba, mediante circular dirigida a los cónsules dominicanos en 1881, que, con la anhelada llegada de inmigrantes del continente mencionado, se pretendía moralizar la población local, eliminar las revueltas, fomentar la educación

4 Mintz, Sidney W., "La resistencia cultural y la fuerza de trabajo en el Caribe", El Caribe Contemporáneo, No. 6, Facultad de Ciencias Políticas y Sociales, UNAM y Centro de Estudios Latinoamericanos, México, 44.

5 Guerra, Ramiro, Azúcar y población en las Antillas, Editorial de Ciencias Sociales, La Habana, 1976, 38; Watts, David, Las Indias Occidentales. Modalidades de desarrollo, cultura y cambio medioambiental desde 1492, Alianza Editorial, Madrid, 1992, 487-488.

6 National Archives. Colonial Office, Londres, 318/332. Comunicación del 4 de febrero de 1914. 
y el trabajo; por ello, destacó los esfuerzos realizados en favor de la agricultura, el comercio y la industria7, aspectos clave para alcanzar el ansiado objetivo.

Por su parte, Wenceslao Figuereo, encargado del Ministerio de Interior y Policía en el segundo mandato del general Ulises Heureaux, expuso que un requisito previo para alcanzar el progreso era apaciguar las guerras civiles animadas por caudillos regionales. Cierto es que, una vez finalizadas estas en 1890, el país vivió un periodo de paz que se atribuyó a tres factores: primero, la actitud sana y pacífica de los dominicanos; segundo, la política conciliadora de la administración del Estado, y tercero, la observancia del bien común. Estos tres elementos constituirían, según Figuereo, las bases del progreso. A ellos se sumaban las ventajas de la instrucción pública, el amor al trabajo, el cambio de hábitos y costumbres, el desarrollo comercial y el fomento de la industria. Dos ejemplos de la conjugación de aquellos elementos en favor del desarrollo fueron: primero, la puesta en servicio de la vía férrea que unía las ciudades de Puerto Plata, en la costa atlántica, con la ciudad de Santiago de los Caballeros, en la parte central de la isla ${ }^{8}$; y segundo, la construcción la línea férrea que unía el puerto de Sánchez con La Vega, en claro interés de fortalecer las exportaciones de la región del Cibao para dinamizar la producción agrícola y activar el comercios?

Afirmó el ministro figuereo que la política de justicia, orden y progreso, aplicada en su administración, había propiciado un clima de paz que hizo posible la creación de la Sociedad Económica de Agricultura, para impulsar la inmigración con el propósito de explotar los bosques de Azua y Barahona en el sur oeste del país; y que era necesario destinar recursos para la creación de otras instituciones similares. Sobre el particular expresó:

"...y creo, ciudadano presidente, que la inmigración en escala considerable sería el [medio] más poderoso para transformar en vastísimo emporio los bosques seculares de Azua, Neyba, Barahona y la Maguana, así como los inmensos valles fronterizos".

7 Grullón, Eliseo, “Circular al Cuerpo Diplomático y Consular de la República”. Santo Domingo, Gaceta Oficial, año, 8 de enero de 1881, BNPHU, No. 343.

8 La vía férrea fue inaugurada en 1897.

9 Las construcciones de vías férreas eran tenidas como paso importante de progreso. Fiel a ese propósito, se otorgaron concesiones a Samuel A. Fowle, Everett D. Godfrey y Henry L. Bean para construir una que uniera Azua, en la costa sur, con la bahía de Manzanillo, en la costa norte. Gaceta Oficial, 6 de mayo de 1893. 
Constituida con ese patriótico fin la sociedad "Económica de Agricultura \&" en la ciudad del Vía, aguarda ansiosa el momento en que sea permitido al Gobierno proteger los esfuerzos que ella desea prodigar a favor de la inmigración y de otras útiles empresas. Y en términos generales, existen en toda la República asociaciones establecidas con idénticos fines; pero mientras al Despacho de lo Interior no fuere dado disponer con propia iniciativa de algunos fondos para impulsar el adelanto de los pueblos, la acción Gubernativa será lenta y débil acerca de este punto, que recomiendo a la alta penetración de Ud."10

Uno de los factores que el ministro Figuereo resaltó en su mensaje al presidente Heureaux fue el deber de conservar el orden público. El énfasis en este elemento es entendible a partir de un incidente paradigmático en la sociedad dominicana acaecido en 1886. En aquel año, los partidarios de los generales Benito Monción y Casimiro de Moya se rebelaron contra la administración elegida'1 . Este alzamiento situó al país en un estado de guerra que se prolongó hasta los últimos dos meses de 1888. En marzo de 1890, Pablo Reyes se vinculó al grupo de los antigubernamentales y lideró un movimiento revolucionario 12. Ambas acciones alteraron el clima de paz y quebrantaron tanto la estabilidad propicia para el arribo de inmigrantes, como la inversión de capitales. Procurando cambiar el estado de las cosas, los funcionarios dominicanos se dispusieron a impulsar el discurso de la paz. Figuereo, en calidad de Ministro de Interior, destacaba la interrelación entre el progreso y los factores necesarios para alcanzar la paz: la observación de las leyes, la política conciliadora desde el Estado, y el respecto al bien común 13. Por su parte, el presidente Ulises Heureaux afirmaba que el progreso y la paz eran las bases que atraerían a los inmigrantes europeos y les permitiría establecerse en el territorio nacional.

10 Figuereo, W., “Memoria que al ciudadano Presidente de la República presenta el Secretario de Estado de lo Interior y Policía". Gaceta Oficial, año. XVIII, 15 de febrero de 1891, BNPHU, No. 866.

11 Jarvis Luis, Rafael, "Ulises Heureaux: la coyuntura política de 1888 a través de sus correspondencias", en País Cultural. Ministerio de Cultura. Año IX, Número 16. Octubre de 2014, 68-78.

12 Hubo otros movimientos contra el régimen político, como la expedición del vapor Fanita en 1898.

13 Figuereo, W., "Memoria que al ciudadano Presidente de la República presenta el Secretario de Estado de lo Interior y Policía". Santo Domingo, año. XVIII, Gaceta Oficial, 15 de febrero de 1891, BNPHU, No. 866. 


\section{Decisiones en favor de la inmigración. La creación de Juntas}

Con el propósito de impulsar el avance del país promoviendo la inmigración europea, las autoridades dominicanas emitieron decretos, resoluciones y leyes otorgando facilidades a quienes desearan establecerse en el territorio nacional. Al parecer, el contexto era favorable porque desde Europa llegaban migrantes hacia el continente americano $y$, en el territorio dominicano, las tierras donde podrían asentarse eran vastas. En 1871, una Comisión estadounidense que visitó el país con el propósito de evaluar las condiciones materiales de la nación, estimó la población dominicana en 150.000 habitantes 14 ; en base a esta cifra, se deduce una baja densidad de 3.09 hab. $/ \mathrm{km}^{2}$, lo cual hacia deseable incrementar el número de residentes que se dedicaran a poblar el territorio e incrementar la producción.

En 1875, el ministro de interior Juan Bautista Zafra, en una carta dirigida a los gobernadores de provincias y de distritos, llamaba la atención sobre la necesidad de fomentar la inmigración por ser portadora de riqueza, tal como era visible en algunos países del continente americano. Incluso indicaba los medios para atraerla. Como referente aludía a los beneficios de la inmigración en Argentina y Cuba ${ }^{15}$. Un aspecto que el Ministro Zafra resaltó fue el conjunto de decisiones que las autoridades de los países citados emitían con el fin de atraer inmigrantes: se habían dictado decretos y leyes otorgando franquicias, se crearon Juntas de Inmigración, se firmaron contratos con empresas agrícolas de colonización o dedicadas a su fomento, y se dispuso la exoneración de impuestos a las importaciones de diversos tipos, tanto a compañías como a personas naturales. Sin embargo, estas mismas decisiones cosecharon pocos resultados cuando fueron tomadas por el estado dominicano ${ }^{16}$.

14 El presidente Buenaventura Báez mantuvo el interés de anexar la República Dominicana a los Estados Unidos, quienes enviaron una comisión de evaluación. Informe de la Comisión de investigación de los E. U. A. en Santo Domingo en 1871. Prefacio y notas de E. Rodríguez Demorizi, Editora Montalvo, Ciudad Trujillo, 1960, 75 (Academia Dominicana de la Historia IX).

15 Bautista Zafra, Juan, "Ministerio de lo Interior y Policía. Circular a los Gobernadores de las Provincias y Distritos". Santo Domingo, Gaceta Oficial, año. II, 5 de octubre de 1875, BNPHU, No. 91.

16 Congreso Nacional. "Decreto No. 263 del Congreso Nacional sobre inmigración abril 1852". Santo Domingo, Colección de Leyes, Decretos, y Resoluciones emanadas de los poderes Legislativo y ejecutivo de la República Dominicana, tomo segundo. Santo Domingo, Imprenta del Listín Diario, 1927, 351-353. Colección de Leyes, Decretos y Resoluciones emanadas de los poderes Legislativo y Ejecutivo de la República Dominicana, tomo cuarto, Santo Domingo, Imprenta del Listín Diario, 1927, 77-78. Congreso Nacional. "Declarada la urgencia". Santo Domingo, BNPHU, El Monitor periódico oficial del gobierno dominicano , año 3, 27 de abril de 1867, No. 86 . El 31 de julio de 1867, el presidente José María Cabral emitió el decreto 1069 que anulaba el inciso segundo del artículo primero del Decreto del Congreso Nacional, en el sentido de que no era obligatorio para los inmigrantes adquirir la nacionalidad dominicana. Cabral, José María, "Decreto No. 1069 del Poder Ejecutivo derogando el segundo inciso, art. $1^{\circ}$ del Decreto del Congreso Nacional de fecha 22 de abril del año corriente, 31de julio de 1867". Colección de Leyes, Decretos y Resoluciones emanadas de los poderes Legislativo y Ejecutivo de la República Dominicana, tomo quinto. 
En 1876, durante la segunda administración gubernamental del general Ignacio María González, el Poder Ejecutivo recibió diversos proyectos destinados a impulsar la agricultura y la industria, lo cual permitiría generar atractivas condiciones de vida para los esperados migrantes europeos. En ese sentido, fueron creadas las Juntas de Fomento. A través de ellas, el presidente se proponía alcanzar "mejor orden, limpieza, higiene y ornato de las localidades"17, a la vez que se deseaba impulsar el cultivo de frutos exportables que aseguraran buenos precios en el mercado internacional. Dichas Juntas fueron instaladas en la capital del país, Santo Domingo de Guzmán; en las cabeceras de provincia: Compostela de Azua, Santa Cruz del Seibo, Santiago de los Caballeros, Concepción de La Vega y en los distritos de Puerto Plata y Samaná ${ }^{18 .}$

Uno de los pocos gobernantes que promovió el desarrollo nacional, disponiendo de los recursos del país, fue el general Gregorio Luperón. Durante su administración interina favoreció la creación de Juntas de Artes y Oficios en cada común ${ }^{19}$. Luperón se valió de la influencia moral, espiritual y educativa que ejercía la Iglesia sobre la población para incorporar un representante de esta institución entre los miembros integrantes de las Juntas. Las Juntas de Artes y Oficios pretendían captar el interés de los jóvenes, cuyas edades estaban comprendidas entre los 14 y 18 años, para dotarlos de los conocimientos prácticos que les permitieran aportar al progreso de su localidad. A los alumnos se les eximió de prestar el servicio militar durante el tiempo que durara su formación, a la vez se obsequió un solar a cada maestro de ese proyecto.

A partir de 1891 cambió la estrategia legislativa orientada a promover la inmigración. Los ayuntamientos pasaron a tener mayor protagonismo en las propuestas y con tal propósito fue fundada una Junta Provincial de Inmigración en cada cabecera de provincia. En 1895 las autoridades retomaron el interés en fundar

Santo Domingo, Imprenta Listín Diario, 1927, 178-179. Gonzalez, Ignacio M., "El Poder Ejecutivo de la República Domincana". Santo Domingo, Gaceta de Santo Domingo, año 1, Martes 21 de julio 1874, BNPHU, No. 28. La Gaceta, periódico del Estado dominicano, no enumeraba las páginas en esa época por lo que las citas que se hagan de ese medio informativo en lo adelante quedarán sin número de página. De igual manera, quedarán sin la numeración del ejemplar porque al cambiar la administración del Estado, esta iniciaba con una nueva numeración.

17 Gonzáles, Ignacio M., "Decreto No. 1298 del Poder Ejecutivo creando Juntas de fomento, Santo Domingo, 6 de junio de 1874". Colección de Leyes, Decretos y Resoluciones emanados de los poderes Legislativo y Ejecutivo de la República Dominicana, tomo sexto. Santo Domingo, Imprenta del Listín Diario, 1928, 69.

18 Tolentino Rojas, Historia de la división territorial, 2da. Edición, Sociedad Dominicana de Bibliófilos, Santo Domingo, 1993, 153.

19 Los integrantes eran el gobernador, el Jefe Comunal, el Párroco, el director del Colegio o Escuela municipal donde estaría el taller, el Presidente y el Secretario del Ayuntamiento. 
Juntas Provinciales con el propósito era captar agricultores y obreros con familia ${ }^{20}$. Fueron fundadas algunas Juntas en la capital, así como en los Distritos de Monte Cristi, Puerto Plata, y en el Puerto de Sánchez. Dichas juntas estaban integradas por el Gobernador, el presidente del Ayuntamiento, el Síndico, los Interventores de Aduana, un comerciante y un agricultor.

Animadas las autoridades, por el creciente número de inmigrantes cubanos y puertorriqueños que llegaban al país, anunciaron la fundación de una "Junta Central de Inmigración" presidida por el ministro de Fomento y Obras Públicas. Las Juntas de Fomento, fundadas con anterioridad en los comunes, dependerían de ella ${ }^{21}$. El entusiasmo llegó a la Cámara de diputados donde sometieron a discusión la conveniencia de disponer el $25 \%$ de los ingresos de la renta aduanera de La Romana para fomentar la inmigración. Respecto a las ventajas ofrecidas a los beneficiarios de las Juntas de Fomento el diputado Morales L. propuso otorgarles 18 1 1 2 tareas de tierra y 40 centavos diarios a las familias asentadas 22 .

\section{Incentivos y exoneraciones}

Otra estrategia empleada para atraer migrantes europeos fue el ofrecimiento de incentivos. El 8 de julio de 1876, el presidente Ulises Francisco Espaillat otorgó terrenos estatales a todo aquel que los cultivara con uno o más productos como caña de azúcar, café, cacao, tabaco y algodón, entre otros rubros23. Si la administración de Espaillat obsequiaba terrenos sin límite de extensión, la de Cesáreo Guillermo fijó el área ofrecida en 30 acres $^{24}$. Mandaba que a los extranjeros contratados por los propietarios de fincas rurales o compañías se les exonerase de los impuestos sobre los utensilios de uso doméstico que trajeran al país desde su punto de embarque. Al igual que en tiempos de Espaillat, también se les concederían tierras a todos los que

20 Heureaux, Ulises, "Resolución No. 3566 del P. E. creando Juntas de Inmigración en esta Capital, en los Distritos de Monte Cristy y Puerto Plata y en el puerto de Sánchez". Colección de Leyes, Decretos y Resoluciones Emanados de los Poderes Legislativo y Ejecutivo de la República Dominicana, tomo décimo tercero. Santo Domingo, Imprenta del Listín Diario, 1929, 604-605.

21 El Nuevo Régimen, 8 de agosto de 1900, p. 1.

22 Congreso Nacional, "Sesión del 15 de mayo de 1901". Santo Domingo, Gaceta Oficial, año XXVII, 16 de noviembre de 1901, BNPHU, No.1422.

23 Congreso Nacional, "Ley No. 1548 sobre la concesión gratuita de los terrenos del Estado". Colección de Leyes, Decretos y Resoluciones emanados de los poderes Legislativo y Ejecutivo de la República Dominicana, tomo séptimo. Santo Domingo, Imprenta del Listín Diario, 1929, 89-91.

24 Congreso Nacional, "Ley 1780 Ley de Inmigración”. Colección de Leyes, Decretos y Resoluciones de los poderes, tomo 7mo, Santo Domingo, Imprenta Listín Diario, 1929, 511-513. 
llegaran de manera voluntaria y sin contratos. La política de atracción de inmigrantes europeos continuó en los años siguientes, un ejemplo de ello fue el reparto de tierras estatales bajo el gobierno del presidente Francisco Gregorio Billini en 188425.

Ante el escaso número de inmigrantes europeos que arribaba al país, las autoridades dominicanas destinaron mayores recursos para beneficiar a los extranjeros que decidieran asentarse en la isla. El Congreso Nacional aprobó, en junio de 1884, que se asignara el $30 \%$ de los ingresos de exportación para este fin 26 . El Estado dominicano también exoneró del pago de derecho de puerto a los buques que transportaran potenciales inmigrantes y, en el mismo sentido, ofreció cubrir los gastos de quienes arribaran al país para establecerse. Una muestra de otras disposiciones similares es la concesión otorgada a los señores Montandon Descombes y Cía., fundadores de la colonia de inmigrantes 'La Evolución', ubicada en terrenos de Sabana de la Mar27: ellos fueron exonerados del pago de impuestos a las importaciones que realizaran, por una sola vez, para traer los artículos que necesitaran $y$, de igual modo, recibieron apoyo estatal para emprender el desarrollo de fincas de cacao, café y otros frutos.

Sin embargo, leyes como ésta fueron escasas. El 24 de enero de 1891 también se exoneró de los derechos de puerto a las naves de F. C. Castro, dedicadas al transporte de inmigrantes. Castro había acordado con las autoridades traer al país pobladores de las islas Canarias. Las autoridades le exigieron trasladar un número mayor de 50 personas en cada viaje28. Interesados en que llegara a esas metas, los funcionarios públicos dieron instrucciones al Ministro de Relaciones Exteriores para que, a su vez, comunicara a los cónsules dominicanos la expedición gratuita de salvoconductos a quienes desearan migrar contactados por F. C. Castro. La gracia

25 Congreso Nacional, “Ley Núm. 2290 creando en cada común o cantón una Junta que se denominará de "agricultura e industria". Colección de leyes, decretos y resoluciones emanados de los poderes legislativo y ejecutivo de la República Dominicana. Año 1884, tomo noveno. Santo Domingo, Imprenta del Listín Diario, 1929, 234-237.

26 Congreso Nacional, "Resolución 2270 del Congreso Nacional sobre el 30\% de exportación para la inmigración. Colección de Leyes, Decretos y Resoluciones emanados de los poderes Legislativo y Ejecutivo de la República Dominicana, tomo 9no., Santo Domingo, Imprenta del Listín Diario, 148-149.

27 Congreso Nacional, "Resolución No. 2778 del Congreso Nacional aprobando la concesión otorgada por el P. E. en fecha 13 de marzo de 1888 á los Sres. Montandon Descombes y Cía., fundadores de la colonia de inmigrantes extranjeros "La Evolución, en terrenos de Sabana de la Mar". Santo Domingo, Gaceta Oficial, 28 de junio de 1889. Colección de Leyes, Decretos y Resoluciones emanados de los poderes Legislativo y Ejecutivo de la República Dominicana, tomo undécimo, Santo Domingo, Imprenta del Listín Diario, 1928, 171-177.

28 Gautier, M.M., "Resolución Núm. 2981 del V. P. de la R., en ejercicio de la Presidencia, concediendo al Sr. F. C. de Castro la exoneración de los derechos de puerto para los buques que dedique al transporte de inmigrantes". Colección de leyes, decretos y resoluciones emanados de los poderes legislativo y ejecutivo de la República Dominicana. Año 1891, tomo décimo segundo. Santo Domingo, Imprenta del Listín Diario, 1929, 11. 
que se le otorgaba al beneficiario era por un año, condición que ponía a la puerta del fracaso la empresa, debido al tiempo de travesía desde Europa hasta la isla y la rentabilidad que obtendría.

\section{Fracaso de la inmigración procedente de Europa}

Teófilo Cordero Bidó, ministro del gabinete gubernamental de Ulises Hereaux en 1894, expresó un cambio en la posición del Estado respecto al fomento de la inmigración extranjera. Decía que, si había un reducido número de familias inmigrantes radicadas en el país se debía a que pocos hacendados las contrataron29, y que la posibilidad de seguir igual proceder, por parte del Estado, estaba condicionada a la disponibilidad de recursos económicos. Para obtenerlos habría que imponer una tasa al consumo del petróleo. Los integrantes de la Comisión de Fomento del Congreso Nacional, estaban de acuerdo en establecer un impuesto al petróleo, calculando que se obtendría un ingreso de $\operatorname{RD~} \$ 20.000$ anuales, los cuales podrían dedicarse al fomento de la inmigración 30 . A la vez, sin embargo, lamentaban que la inmigración promovida por los hacendados sólo pretendiera solucionar la escasez de obreros y no de familias europeas que se asentaran con el propósito de progresar y no volverse a ir. Afirmaban categóricamente que los trabajadores llegados desde otras islas del Caribe, en su mayoría afrodescendientes, no constituían el tipo de personas que necesitaba el país. La decepción que percibían los funcionarios dominicanos respecto a la ausencia de los esperados migrantes europeos no cambió, por tanto, al conocerse el reporte favorable del Gobernador de San Pedro de Macorís, respecto al arribo de numerosos inmigrantes procedentes de otras islas del Caribe.

Era evidente el resultado adverso en cuanto al ideal de población migrante esperada y las autoridades aducían que diversos factores explicaban el fracaso. El secretario de Fomento e Instrucción Pública identificó la escasez de recursos del erario como uno de los obstáculos para que el migrante europeo eligiese a la República Dominicana como destino; razón por la cual el país tenía que conformarse con

29 Gobierno Dominicano, "Memoria que al Ciudadano Ministro de lo Interior y Policía presenta el Gobernador Civil y Militar de la Provincia de Azua". Santo Domingo, Gaceta Oficial, año. XX, 14 de abril de 1894, BNPHU, No. 1025.

30 Congreso Nacional, "Sesión del 16 de mayo de 1894". Santo Domingo, Gaceta Oficial, año. XXI, 28 de julio de 1894, BNPHU, No. 1040. 
quienes llegaran de manera espontánea ${ }^{31}$. Ponía como ejemplo el intento de convencer a los hacendados de los alrededores de la capital para que contrataran personas por un mínimo de dos años. La propuesta consideraba que el Estado dominicano contribuiría con RD\$8 por cada inmigrante contratado por el tiempo especificado. Esta propuesta encontró una fría acogida entre los empresarios, ya que sólo uno se interesó.

El secretario de estado J. T. Mejía, en su memoria dirigida al presidente de la república, llamaba la atención sobre las exiguas inversiones efectuadas para atraer inmigrantes32. Afirmaba que el país no había hecho suficientes sacrificios para captarlos porque los obreros y los capitales habían llegado al país de modo voluntario. Se refería a la migración de empresarios cubanos que, con el inicio de la guerra en 1868, se asentaron en Puerto Plata y San Pedro de Macorís trayendo consigo provechosos avances técnicos. Al momento de redactar su informe Mejía afirmaba que, de un tiempo a esa fecha, se había detenido el flujo de personas. Un importante aporte señalado por el secretario de Estado J.T. Mejía en su memoria era la distinción entre pobladores y braceros. Para él, los braceros de las Antillas menores, en su mayoría afrodescendientes, eran parte de una población 'transeúnte' con la que no se podría obtener solidez en el progreso; decía que, para dar vida a otras actividades eran necesarios 'pobladores', es decir, personas que fijaran su residencia en el territorio nacional.

La lenta llegada de inmigrantes deseados al país fue motivo de discusión en distintos ámbitos del debate político. Testigos de la época especularon sobre las causas de los escasos resultados de la política inmigratoria. Así, por ejemplo, el diputado Mariano Rodríguez Objío se refirió al fracaso de las leyes y decretos emitidos, así como a las atribuciones otorgadas a los ayuntamientos con esos fines. Afirmaba que, a pesar de contar con algunos indicios del progreso, como el telégrafo, el ferrocarril y los ingenios de caña de azúcar, el país estaba muy retrasado respecto a las naciones del continente, sobre todo en lo referente a las políticas migratorias. Sobre el tema de la inmigración expresó:

31 Mejía, J. T., "Memorias que al Presidente de la República presenta el Secretario de Estado en los despachos de Justicia, Fomento e Instrucción Pública". Santo Domingo, Gaceta Oficial, año XI, 26 de abril de 1884, BNPHU, No. 508.

32 Mejía, J.T., "Memoria que al presidente de la Republica presenta el Secretario de Estado en los despachos de Justicia, Fomento e Instrucción Pública". Santo Domingo, Gaceta Oficial, año. XI, 26 de abril de 1884 BNPHU, No. 508. 
"Un asunto que juzgo de suma importancia para el país me obliga a ocupar vuestra atención, a fin de recabar una ley o Decreto que haga más eficaz cuanto se ha dictado hasta hoy con relación al mismo asunto.

Tiempo hace que el Poder Legislativo, mirando sobre el porvenir del País, ha pugnado por facilitar los medios que conducen a traer inmigraciones útiles, que, a más de aumentar nuestra escasa población, sean factores en el progreso material que tanto necesitamos para desempeñar un puesto digno y respetable entre las naciones del Nuevo mundo.

Solo nosotros, Honorables Diputados, no hemos conseguido gran cosa; verdad que tenemos telégrafos, ferrocarriles, haciendas de caña, etc., que por cierto algo nos complace; pero este progreso muy laborioso y comparado significa que vamos a la cola.

Es evidente que el Estado no puede hoy por hoy, por causas extrañas a la voluntad de sus administradores, iniciar y atender a la inmigración, como no ha podido hacerlo en años atrás a pesar de leyes y decretos. Todo el buen deseo ha quedado reducido a papeles, nada se ha podido traducir en hechos; $y$, no obstante, es preciso hacer, es preciso aumentar nuestra población para hacernos más respetables y garantizar la nacionalidad"33."

Como afirmara el diputado Rodríguez Objío, algunas leyes aisladas habían puesto parches a la tímida política migratoria sin obtener mayores resultados. Un ejemplo de eso ocurrió en la sesión legislativa del 25 de julio de 1884, donde aprobaron la resolución 2270 que autorizaba al Poder Ejecutivo el uso del 30\% de los ingresos de exportación para el fomento de la inmigración ${ }^{34}$.

En 1894 los funcionarios diplomáticos participaron en la promoción de la inmigración, aunque no tuvieron suficiente iniciativa. José Engo, cónsul dominicano en España, informaba al ministro de Relaciones Exteriores que la migración desde el país Ibérico se dirigía a Costa Rica, y que estaba paralizada la que se dirigiría a Brasil

33 Congreso Nacional, "Poder Legislativo". Santo Domingo, Gaceta Oficial, año, XVIII, 26 de septiembre de 1891, BNPHU, No. 892.

34 Congreso Nacional, "Resolución No. 2270 del Congreso Nacional autorizando al Poder Ejecutivo a seguir disponiendo del $30 \%$ de los derechos de exportación aplicado a la inmigración". Santo Domingo, 28 de julio de 1884, Colección de Leyes, Decretos y Resoluciones emanadas de los poderes Legislativo y Ejecutivo de la República Dominicana, tomo noveno, Santo Domingo, Imprensta del Listín Diario, 1929, 148-149. 
debido a la guerra que vivía aquel país35. A la vez, se limitaba a informar que su despacho otorgaría la visas de inmigrante hacia la República Dominicana a quienes la solicitaran. Claramente, era una acción muy pasiva porque en esos momentos el país vivía un tiempo de paz estable y aún existían condiciones favorables que podían ofertarse ${ }^{36}$. Con mayor énfasis hubiera destacado las bondades del país porque en el siguiente año, el mismo funcionario, informaba que la migración a Costa Rica estaba paralizada ${ }^{37}$.

Las informaciones remitidas por los cónsules destacados en otras ciudades europeas se limitaban a reportar la salida de viajeros desde diferentes puertos, sin decir qué hacían para dar a conocer las ventajas que ofrecía la República Dominicana a los potenciales migrantes. El 28 de febrero de 1898, Armando Canevaro, cónsul dominicano en Italia, explicaba en informe al Ministro de Exteriores el movimiento migratorio desde ese país. Señalaba que entre 1896 y 1897 las salidas desde el puerto de Génova habían aumentado un 10\% respecto al periodo anterior, siendo EE. UU., Brasil, Argentina y Centro América los destinos preferentes en el continente americano ${ }^{38}$. En años posteriores, el Cónsul General Dominicano en Italia comentaba al superior suyo en Santo Domingo un nuevo dato: la única exigencia que las autoridades italianas solicitaban para permitir la emigración de sus conciudadanos era la firma de un contrato39. En su informe no dejaba claro si dicho contrato lo debían firmar representantes o empresarios del país receptor donde se esperaba que laboraran quienes abandonaran la península, pero quedaba claro que la frontera entre la iniciativa pública y la privada, con el propósito de fomentar la inmigración, era muy delgada.

Desde otros sectores estatales los funcionarios no escatimaban esfuerzos para atraer inmigrantes al país. Tal es así que, durante la Exposición Universal de París en 1889, Henri Thomasset40 se preguntaba en el informe enviado al ministro de Fomento:

35 El proceso del advenimiento de la época republicana en 1889 , y las contradicciones entre los diferentes sectores involucrados, provocó un levantamiento de la Marina.

36 Engo, José, "Consulado Dominicano en Cádiz". Gaceta Oficial, año. XXI, 25 de agosto de 1894, BNPHU, Gaceta Oficial, No. 1044.

37 Engo, José, "Ministerio de Relaciones Exteriores". Santo Domingo, Gaceta Oficial, No. XXII, 9 de febrero de 1895, BNPHU, No. 1068. Reportaba que algunos españoles, contratados por compatriotas asentados en Santo Domingo, habían salido de Cádiz.

38 Canevaro, Armando, “Consulado General de la República Dominicana en Génova, año. XXV, 9 de abril de 1898, BNPHU, No.1233.

39 Gobierno Dominicano, "Documentos anexos a la Memoria del Ministro de Relaciones Exteriores". Santo Domingo, Gaceta Oficial, año XXIII, 3 de octubre de 1906, BNPHU, No. 1726.

40 Henri Thomasset, ingeniero francés que arribó a a la República Dominicana a principios de la octava década del siglo $\mathrm{XIX}$, desarrolló diversos estudios, diagnósticos y proyectos; entre ellos: el plano de la ciudad de La Romana, el trazo 
"¿cuánto hubiese pensado en la presencia de una comisión experta que, en el Pabellón Dominicano, hubiese satisfecho las preguntas de los visitadores, con informes exactos acerca del país, sobre sus necesidades y ventajas sobre otros?" 41 . El mismo autor del informe propuso un cuadro comparativo de las bondades que podía ofertar el país respecto a otros 11 territorios insulares del Caribe. De ellos, la República Dominicana tenía la más baja densidad poblacional, con 7 hab./Km², mientras que Cuba era el país que más se aproximaba a esta cifra, con 13 hab/Km²; el territorio de mayor densidad poblacional era Barbados, con $400 \mathrm{hab} / \mathrm{Km}^{2}$. Este parámetro sugerido por Thomasset para atraer inmigrantes era sólo uno de los que debía tomarse en consideración. Los integrantes del gabinete gubernamental opinaron que el personal enviado al pabellón dominicano en París no alcanzó a cumplir una labor eficiente y determinante para captar a los potenciales inmigrantes. Igualmente consideraban que diversos factores se interponían con mayor fortaleza a esa situación.

\section{Nueva percepción sobre los inmigrantes}

La preferencia por inmigrantes de origen caucásico guardaba relación con la idea de progreso vinculada a las concepciones darwinistas que, aplicadas a la sociedad, atribuían mayores probabilidades de desarrollo a esta población42.

de la vía férrea para unir a San Cristobal con la ciudad capital, la construcción de la Iglesia Parroquial Mayor de Santiago de los Caballeros, el diseño del acueducto de Puerto Plata y el plano para la construccion de los ferrocarriles del este; escribió un interesante opúsculo sobre la ciudad de San Cristobal, entre otros.

41 "Ministerio de Fomento y Obras Públicas". Santo Domingo, año. XVIII, 17 de enero de 1891, BNPHU, No. 856 Documentos Anexos a la Memoria del Ministro de lo Interior y Policía, Expediente No. 7. Santo Domingo, Gaceta Oficial, año XVIII, 17 de enero de 1891, No. 856 y Gobierno Dominicano. Documentos Anexos a la Memoria del Ministro de lo Interior y Policía, Expediente No. 7. Santo Domingo, Gaceta Oficial, año XVIII, 24 de enero de 1891, BNPHU, No. 857. En adelante será citado como "Ministerio de Fomento y Obras Públicas".

42 Por ejemplo: Naranjo Orovio, Consuelo, "Immigration, Race and Nation in Cuba in the Second Half of the XIX Century", Ibero-Amerikanisches Archiv (Monográfico: Race, Society and Culture in Afro-Latin America) vol. 24, núms. 3-4: 1-00, Berlin, 1998, 303-326. Naranjo Orovio, Consuelo y García Armando, “Inmigraciones e 'higiene racial' en Cuba, 1900-1940", en José G. Cayuela (coord.), Un Siglo de España: Centenario 1898-1998, Universidad de CastillaLa Mancha/Cortes de Castilla-La Mancha, Cuenca, 1998, 437-449. Naranjo Orovio, Consuelo, "Inmigración española e imaginario nacional en Cuba, 1900-1920", en Mauricio Font and Alfonso Quiroz (eds.), The Cuban Republic and Jose Marti: Reception and Use of a National Symbol, Lexington Books, Lanham, Maryland, 2006, 155-170. Naranjo Orovio, Consuelo y Petinnà, Vanni, “Un nuevo orden: inmigración y prejuicios sociales en Cuba, 1900-1930”, en Pablo Yankelevich (coord.), La nación y extranjería en América Latina. Normas y prácticas de exclusión en las políticas migratorias, UNAM-ENAH, México, 2009, 95-145. Naranjo Orovio, Consuelo, Las migraciones de España a Iberoamérica desde la Independencia, CSIC, Madrid, 2010. Naranjo Orovio, Consuelo, "Debates en torno a la inmigración en Cuba, 1800-1930", en Josef Opatrný (coord.), Migraciones en el Caribe hispano, Editorial Carolinum, 2012, 25-39. Nisbet, Robert, 258-259. Ruiz, Rosaura, Puig-Samper, Miguel Ángel y Zamudio, Graciela (eds.), Darwinismo, Biología y Sociedad, UNAM/Doce Calles, México/Madrid, 2013. Puig-Samper, Miguel Ángel, Orrego, Francisco, Ruiz, Rosaura Ruiz y Uribe, J. Alfredo (eds.), Yammerschuner. Darwin y la darwinización en Europa y América Latina, Ed. Doce Calles-UNAM-DIBAM, Madrid-México-Santiago de Chile, 2014. 
Aquellas eran ideas propias del discurso de progreso que llegaron al continente americano en el siglo XIX43. Quienes esperaban recibir migrantes europeos en la República Dominicana utilizaron en varias ocasiones las teorías sobre la aptitud de determinados pueblos para el trabajo y para emprender iniciativas que condujeran al progreso. En las memorias de 1882, el secretario de Estado de Interior informaba que llegarían al país migrantes desde Alsacia y Lorena44. Por su parte, el presidente Francisco Billini también favorecía la entrada de personas de otras latitudes, tal y como expresó en enero de 1883, cuando abogaba por la llegada de belgas e hindúes. Coincidiendo con Billini, Julien reservaba a los hindúes el trabajo agrícola y a los belgas el artesanal en los talleres de artes y oficios 45 , porque los europeos no eran aptos para trabajar en la industria azucarera ${ }^{46}$.

El entusiasmo por la idea ofrecer ventajas a más migrantes llegó a la Cámara de Diputados, donde sometieron a discusión la conveniencia de disponer del $25 \%$ de los ingresos de la renta aduanera de la provincia dominicana de La Romana para fomentar la inmigración. El diputado Morales L. propuso otorgar a los beneficiarios 18 $1 / 2$ tareas de tierra y 40 centavos diarios a las familias asentadas 47 . Durante la administración del Presidente Billini también se firmó un contrato con Andrés Sosvilla y González, capitán de marina mercante española, para que transportara al territorio nacional el mayor número de familias o individuos de las islas Canarias a cambio del pago de RD $\$ 20$ por cada persona entre 10 y 60 años ${ }^{48}$.

A partir de 1850, cuando las administraciones gubernamentales domínicoinglesas firmaron el tratado de amistad, comercio y navegación, la República Dominicana abrió sus puertos al arribo de numerosos súbditos británicos del Caribe. Una muestra de ello es el registro de los que arribaron a Puerto Plata en 1871: de estos,

43 Weinberg, Gregorio, La ciencia y la idea de progreso en América Latina, 1860-1930, Fondo de Cultura, 2 da. México, 1998, 49- 63.

44 Heureaux, U., “Mensaje del Presidente de la República al Congreso Nacional”. Santo Domingo, año XI, 8 de abril de 1882, BNPHU, No. 408.

45 Informaba que el pasaje para traer a un hindú ascendía a RD\$50. El pago por un día de trabajo en los lugares donde menos pagaban era de 30 centavos. "Emigración belga" en el Eco de la Opinión, 12 de enero de 1883. No. 185. Reproducido en Blanco Díaz, Andrés (ed.), Francisco Gregorio Billini. Más que un Eco de la Opinión. 2. Escritos, 18791885, Editora Búho, Santo Domingo, 2009, 213-215.

46 Julient, L., "La cuestión de inmigración de trabajadores extranjeros para Santo Domingo". Santo Domingo, Gaceta Oficial, año. X, 11 de agosto de 1883, BNPHU, No. 477.

47 Congreso Nacional. "Sesión del 15 de mayo de 1901". Santo Domingo, Gaceta Oficial, año XXVII, 16 de noviembre de 1901, BNPHU, No.1422.

48 Congreso Nacional “Contrato No. 2244 celebrado por el Ministro de Fomento sobre inmigración”. Colección de Leyes, Decretos y Resoluciones Emanados de los Poderes Ejecutivo y Legislativo de la República Dominicana, tomo 9no. Santo Domingo, Imprenta del Listín Diario, 1929, 243-247. 
la mayor cantidad eran migrantes de las islas angloparlantes, seguidos de cubanos, estadounidenses, daneses, españoles, franceses, haitianos y puertorriqueñas, entre otros. El siguiente cuadro ilustra los números de personas extranjeras por nacionalidades en la ciudad de Puerto Plata en la fecha antes indicada:

\begin{tabular}{|c|c|c|c|c|c|c|}
\hline Procedencia & \multirow{2}{*}{$\mathbf{N}^{\circ}$} & \multirow{2}{*}{$\%$} & \multicolumn{4}{|c|}{ Sexo } \\
\cline { 4 - 7 } & & & \multicolumn{2}{|c|}{ Masculino } & \multicolumn{2}{c|}{ Femenino } \\
\hline Inglesa & 311 & $10.09 \%$ & 158 & $5.19 \%$ & 153 & $4.96 \%$ \\
\hline Cubana & 197 & $6.39 \%$ & 105 & $3.41 \%$ & 92 & $2.99 \%$ \\
\hline Americana & 85 & $2.76 \%$ & 39 & $1.27 \%$ & 46 & $1.49 \%$ \\
\hline Danesa & 84 & $2.73 \%$ & 43 & $1.40 \%$ & 41 & $1.33 \%$ \\
\hline Española & 57 & $1.85 \%$ & 51 & $1.65 \%$ & 6 & $0.19 \%$ \\
\hline Francesa & 53 & $1.72 \%$ & 33 & $1.07 \%$ & 20 & $0.65 \%$ \\
\hline Haitiana & 51 & $1.65 \%$ & 20 & $0.65 \%$ & 31 & $1.01 \%$ \\
\hline Portorriqueña & 48 & $1.56 \%$ & 29 & $0.94 \%$ & 19 & $0.62 \%$ \\
\hline Alemana & 36 & $1.17 \%$ & 27 & $0.88 \%$ & 9 & $0.29 \%$ \\
\hline Venezolana & 24 & $0.78 \%$ & 17 & $0.55 \%$ & 7 & $0.23 \%$ \\
\hline Holandesa & 16 & $0.52 \%$ & 15 & $0.49 \%$ & 1 & $0.03 \%$ \\
\hline Asiática & 6 & $0.19 \%$ & 6 & $0.19 \%$ & 0 & $0.00 \%$ \\
\hline Italiana & 5 & $0.16 \%$ & 5 & $0.16 \%$ & 0 & $0.00 \%$ \\
\hline Africana & 2 & $0.06 \%$ & 1 & $0.03 \%$ & 1 & $0.03 \%$ \\
\hline Milanesa & 1 & $0.03 \%$ & 1 & $0.03 \%$ & 0 & $0.00 \%$ \\
\hline Mejicana & 1 & $0.03 \%$ & 1 & $0.03 \%$ & 0 & $0.00 \%$ \\
\hline Chilena & 1 & $0.03 \%$ & 1 & $0.03 \%$ & 0 & $0.00 \%$ \\
\hline No registrada & 1 & $0.03 \%$ & 1 & $0.03 \%$ & 0 & $0.00 \%$ \\
\hline Migrante & 979 & $31.77 \%$ & 553 & $17.94 \%$ & 426 & $13.82 \%$ \\
\hline Dominicana & 2.103 & $68.23 \%$ & 904 & $29.33 \%$ & 1.199 & $38.90 \%$ \\
\hline Total & 3.082 & $100.00 \%$ & 1.457 & $47.27 \%$ & 1.625 & $52.73 \%$ \\
\hline
\end{tabular}

Residentes extranjeros en Puerto Plata, 1871. Fuente: Archivo General de la Nacional. Junta Central Electoral. Censo del Honorable Ayuntamiento de Puerto Plata del año 1871. IT: 1701796.

Aunque dichas cifras no podrían generalizarse para todo el país, ponen de manifiesto cuáles fueron las islas de procedencia de los inmigrantes británicos. A partir de 1876 las autoridades dominicanas dejaron de manifestar su expresa preferencia por atraer migrantes procedentes de Europa: la realidad les demostraba el arribo al país de numerosos cubanos o puertorriqueños. Estos últimos se habían rebelado contra el gobierno colonial español en 1868 y habían migrado por causa de la guerra y por persecución política.

Más tarde se produjo un receso respecto a la expedición de normas en materia migratoria: transcurrieron siete años entre la resolución emitida en 1884 hasta la que 
se expidió en abril de 189049 y la resolución 3069 emitida en 1891. En aquel tiempo, desde el gabinete ministerial del presidente Ulises Hereaux se presentaron varios proyectos al Concejo de Gobierno sin explicar qué contenían o cuáles eran sus alcances. Sólo se informó que intentaban conciliar las facultades del Poder Ejecutivo con las leyes destinadas a promover las franquicias y la inmigración, palabras que surgieren un cambio drástico en el propósito de fomentar la migración procedente de Europa.

A partir de 1890, el Poder Ejecutivo se enfocó en una nueva visión respecto a la inmigración como tema de Estado. Influyó en ello la ausencia de la esperada inmigración blanca y las crecientes demandas de los inmigrantes angloparlantes y afrodescendientes llegados desde otras islas del Caribe, contratados como obreros en los ingenios azucareros. En este contexto, a finales de septiembre de 1890 una comisión, integrada por los diputados L. P. Braches, J. M. Molina y M. J. Jiménez, opinaba que los proyectos de inmigración y los sacrificios para ponerlos en práctica nunca serían estériles50. Expresaban así su reacción ante las declaraciones del secretario de Estado, quien, desde abril de ese año, informaba haber sometido varios proyectos al Concejo de Gobierno51 y a la Cámara de Diputados, después de presentarlos al presidente de la República.

En 1891, la Resolución 3069 del Congreso Nacional marca el inicio de un segundo periodo respecto al tema estudiado porque transfiere a los ayuntamientos la autorización del gasto de un $5 \%$ de sus ingresos para el fomento de la inmigración. A partir de ese momento, la promoción de la inmigración quedó en manos de los cabildos y de los gobernadores provinciales hasta concluir aquella década. La aplicación de esta Resolución implicaba crear en cada región una Junta Provincial integrada por el Gobernador, el presidente, el Síndico del Ayuntamiento, y un delegado del municipio52.

49 Gobierno Dominicano, "Memoria que al ciudadano Presidente de la República presenta el Secretario de Estado de Fomento y Obras Públicas". Santo Domingo, Gaceta Oficial, año XVII, 19 de abril de 1890, BNPHU, No. 817.

50 Congreso Nacional, "Poder Legislativo" Santo Domingo, Gaceta Oficial, No. XVII, 4 de octubre de 1890, BNPHU, No. 841.

51 Gobierno Dominicano, "Memoria que al Ciudadano Presidente de la República presenta el Secretario de Estado de Fomento y Obras Públicas". Santo Domingo, Gaceta Oficial, No. XVII, 19 de abril de 1890, Biblioteca Pedro Mir Universidad Autónoma de Santo Domingo, No. 817.

52 Congreso Nacional, "Resolución 3069 del C. N. disponiendo que los Ayuntamientos de la República, a fin de dar cumplido efecto a la atribución $9^{\circ}$ sobre fomento e inmigración del país, de sus rentas generales, con exclusión de las de patentes, separen un 5 \%, para atraer la inmigración, 30 de junio de 1891". Colección de Leyes, Decretos y 
La reacción de los funcionarios en los ayuntamientos y gobernaciones fue favorable. El gobernador de Azua informaba, en junio de 1893, que se había nombrado a los miembros de la Junta de Inmigración de su provincia; la presidía el Gobernador, que a su vez fungía como síndico, y la integraban Daniel D. Ortiz, Francisco Calcaño, Francisco Montedeoca y Enrique A. Blandino ${ }^{53}$. El gobernador de El Seibo, Agustín Pérez, en su informe al ministro, comunicaba haber puesto en efecto la Resolución 3069, enviando circulares a los Ayuntamientos ubicados en esa provincia para ordenar que destinaran el $5 \%$ de sus rentas totales al fomento de la inmigración 54 .

El general Ramón Castillo, gobernador civil y militar de San Pedro de Macorís, en su memoria presentada en 1893 al Ministro de Interior, se refirió al buen impacto de la nueva política de inmigración extranjera. Se lamentaba de no poder probar sus palabras con datos estadísticos por la falta de un censo. Esa deficiencia no le impedía confirmar la llegada de numerosos inmigrantes a San Pedro de Macorís atraídos por la oferta de trabajo en la industria azucarera55. A los dos años del informe del general Castillo, en 1895, Dionisio García, gobernador de San Pedro de Macorís, reportaba la existencia de 888 extranjeros. Sin embargo, a consecuencia de la excesiva oferta de mano de obra, el elevado número de trabajadores contratados incidió en la reducción de los salarios pagados a los obreros agrícolas; por lo tanto, no pocos inmigrantes quedaron en la indigencia y tuvieron que retornar a su país de origen. Respecto a los inmigrantes, el gobernador Dionisio García expuso su parecer al Ministro de Interior y Policía. Opinaba que el flujo de puertorriqueños a San Pedro de Macorís había aumentado el año anterior y que había inestabilidad económica entre los agricultores ${ }^{56}$. Lo explicado por el Gobernador al Ministro se redactó en líneas generales, sin entrar a detallar casos específicos, razón por la que se desconoce de manera concreta el número de los puertorriqueños que tuvieron la necesidad de ser

Resoluciones emanados de los poderes Legislativo y Ejecutivo, tomo decimosegundo. Santo Domingo, Imprenta del Listín Diario, 1929,150-152.

53 Campo, Joaquin, "Memoria que al Ciudadano Ministro de lo Interior y Policía presenta el Gobernador Civil y Militar de la Provincia de Azua en 1893". Santo Domingo, año xx, 24 de junio de 1893, BNPHU, No. 983.

54 Perez, Agustin, "Memoria que al Ciudadano Ministro de lo Interior y Policía presenta el Gobernador Civil y Militar de la Provincia Santa Cruz del Seibo en 1893". Santo Domingo, Gaceta Oficial, 22 de julio de 1893, No. 987.

55 Castillo, Ramon, "Memoria que al ciudadano Ministro de lo Interior y Policía presenta el Gobernador Civil y Militar del Distrito de San Pedro de Macorís en 1893". Santo Domingo, Gaceta Oficial, año XX, 26 de agosto de 1893, BNPHU, No. 992.

56 Garcia, Dionisio, "Ministerio de Interior y Policía. Gobernación Civil y Militar de San Pedro de Macorís". Santo Domingo, Gaceta Oficial, año XXII, 28 de septiembre de 1895, BNPHU, N. 1101. 
repatriados. De igual modo, tampoco se conoce la situación de los demás inmigrantes en similar situación.

Un año más tarde, en 1896, otro gobernador de San Pedro de Macorís, José Estay, reportaba al Ministro de Interior que se había contabilizado la llegada de 156 nuevos inmigrantes, en su mayoría cubanos, que huían de la guerra de independencia57. De las palabras del Gobernador se deduce que la Junta de inmigración apoyó a los recién llegados. No precisó, sin embargo, en qué consistió dicho apoyo, si fue alojándolos en albergues temporales o dándoles otro tipo de facilidades.

El número de inmigrantes antillanos británicos se incrementó en el transcurso de los años cuando empezaron a funcionar las centrales azucareros. Respecto a la llegada de haitianos, para trabajar en la misma industria, su incremento no se produjo hasta pasado un periodo mayor a 40 años y fue necesario que se desarrollaran otros hechos históricos. En tanto, a contracorriente de la realidad, algunas autoridades dominicanas continuaban haciendo lo posible por atraer nuevamente inmigrantes europeos al país.

En 1897, Pedro A. Pérez, gobernador de San Pedro de Macorís, en su informe al Ministro de Interior, comunicaba que todos los meses llegaban por aquel puerto personas procedentes de Cuba y Puerto Rico en un vapor español. También arribaban súbditos ingleses desde Tórtola, Saint Thomas, Saint Kitts y Barbados cuando se aproximaba el tiempo de la zafra. Decía el Gobernador que, aunque los ingleses desembarcados no eran numerosos, ni su llegada constante, dejaban siempre beneficios porque se radicaban en el lugar y consumían mercancías. El informe expresaba que la Junta de Inmigración les daba apoyo, sin precisar en qué consistía 58. Otro aspecto que resaltó el informe se refería al asentamiento de esos inmigrantes en el territorio de la provincia: afirmaba que el arribo regular de obreros antillanos británicos contratados por la industria azucarera se produjo en el último tercio del siglo XIX y coincidió con la administración de Ulises Heureaux, quien la hizo viable a través de los permisos que concedió a los dueños de ingenios.

57 Estay, José, "Documentos anexos a la Memoria de Interior y Policía. Gobernación del Distrito de San Pedro de Macorís". Santo Domingo, Gaceta Ofical, año XIV, 5 de septiembre de 1896, No. 695.

58 Pérez, Pedro A., "Memoria que al Ministro de lo Interior y Policía presenta el Gobernador Civil y Militar de San Pedro de Macorís". Santo Domingo, Gaceta Oficial, Año XXIV, 6 de noviembre de 1897, BNPHU, No. 1211. 
En 1907 Manuel Lamarche García, secretario de Fomento, había manifestado igual inquietud en la memoria presentada al presidente de la República. Se refería al caso de Argentina, donde la promoción de la inmigración había tenido éxito y era tenida como paradigma. En este país fue aprobada, en 1876, la Ley Avellaneda de inmigración y colonización, que dio origen a la creación de diversas oficinas dentro y fuera del país para promover, apoyar y dar seguimiento a los extranjeros. Era un sistema organizado que dejó resultados, como pudieron comentar los funcionarios dominicanos59. Igual que la Argentina, Cuba era un país de referencia en materia de promoción de la inmigración. El encargado de Negocios de la Embajada Dominicana en la Habana envió a la Secretaría de Agricultura un informe con sus reflexiones en torno a la legislación cubana respecto al tema60. Descartaba la inmigración de braceros porque, según su criterio, resultaba perjudicial. En cambio, favorecía la de colonos blancos europeos porque aumentaba la producción interna, como entendía que estaba sucediendo. El funcionario, ignorando las leyes de la oferta y la demanda en el mercado laboral, aseguraba que la presencia de los braceros elevaba los salarios. Luego este diplomático se contradecía cuando afirmaba que, en la República Dominicana, gracias a la mano de obra "criolla y de los inmigrantes británicos antillanos", la producción de azúcar podía competir con la de Puerto Rico y Cuba en el mercado de EE. UU.61.

Entrado el siglo XX, la nueva ley de inmigración promulgada por el presidente Eladio Victoria en 1912 repetía el concepto de rechazo a ciertos inmigrantes que emanaba de la Ley de Morales Languasco62. Se prohibía la entrada de minusválidos, enfermos, anarquistas y cualquiera que estuviera impedido de ganarse la vida. Se detuvo la entrada a los viajeros originarios de las colonias europeas en América, Asia y África; también se impedía el ingreso a los braceros de países no europeos. Quienes llegaban debían tener permiso previo de los cónsules dominicanos, de lo contrario

59 Ley 817 de fomento de la inmigración europea de 1876. Consultada en 04/06/2015. http://archivohistorico.educ.ar/ sites/default/files/III_20.pdf

60 Archivo General de la Nación. Secretaría de Estado de Agricultura. Libro \# C-424. Año 1910 17/000853. También existe copia del informe en la Revista de Agricultura. Para la legislación migratoria en Cuba véase: Naranjo Orovio, Consuelo, Del campo a la bodega. Recuerdos de gallegos en Cuba, siglo XX, Ediciós do Castro, A Coruña, 1988; Naranjo Orovio, Consuelo y Petinnà, Vanni, "Un nuevo orden...", 95-145.

61 No era posible que la presencia de los obreros extranjeros elevara los salarios y que el azúcar criollo pudiera competir en el mercado mundial, cuando la regla del comercio internacional es producir a los más bajos costos para competir con productores de otras latitudes, ofertando el producto al más bajo precio. El salario es un costo de la producción y si este se reduce, baja el precio. Si la presencia de los braceros elevaba los salarios y el costo de producción, era imposible que bajara el precio del azúcar ofertado en el mercado mundial.

62 Victoria, E., "Ley sobre inmigración". Santo Domingo, Gaceta Oficial, año XXIX, 11 de mayo de 1912, BNPHU, No. 2295. 
serían devueltos en el mismo barco y se multaría al capitán con RD $\$ 100$ por cada persona no deseada que transportara. En cambio, un tratamiento diferente se daría a las personas que en iguales condiciones fueran oriundas de EE. UU. y de las colonias de España en las Antillas, incluso se les suministraría el sustento por ocho días y se les daría terrenos y semillas para la primera siembra.

En la dualidad de permitir o impedir el acceso de un determinado perfil de migrante llamaba la atención cierta inexactitud en cuanto a la definición de conceptos. Se solía confundir entre si los términos colono y bracero. Se deseaba que todo inmigrante fuera colono cuando, en realidad, no lo era necesariamente. El colono es la persona cuyo resultado y ganancia por su trabajo le pertenecen; puede, o no, ser propietario de la tierra que trabaja, pero sí lo es de la cosecha. Muy distinta es la condición del bracero que trabaja por un salario y el valor de la cosecha no le pertenece. El reglamento de la Ley de Inmigración de 1912 llegó incluso a definir bracero como todo aquel que llegara en buque de vela, que penetrara por la frontera terrestre o que llegara en vapor y no fuera pasajero de primera clase63. Era contraproducente dicho criterio, aunque se mantuvo hasta bien entrado el siglo XX, cuando en la documentación se designó a cada uno por las funciones en el proceso de producción. El bracero era la persona que vendía su fuerza de trabajo a un colono o empresa agroindustrial, aunque arribara al país con boleto de primera clase.

Desde 1912, transcurrieron 4 años sin que las autoridades emitieran ordenanzas referidas a la inmigración. La principal causa fue la inestabilidad política que siguió al final abrupto de la administración gubernamental de Ramón Cáceres64. Con su muerte en 1911 se produjo una situación de inestabilidad que fue aprovechada en 1916 por las autoridades de los Estados Unidos de América para ocupar militarmente el país65. Durante los ocho años que duró la Ocupación se suscitaron significativos cambios en la legislación sobre inmigración, especialmente en lo relativo a los braceros. Fue establecido que, al mes de finalizar la zafra, los portadores de permisos de inmigración debían recibir su remuneración y retornar al lugar desde donde habían llegado66. La ley dejaba abierta la posibilidad de que el bracero pudiera permanecer

63 Trujillo, Rafael L., "Reglamento a la Ley de inmigración”. Santo Domingo, Gaceta Oficial, año LVI, 4 de diciembre de 1930, BNPHU, No. 4307.

64 Ramón Cáceres fue baleado el 19 de noviembre de 1911, y ese hecho le causó la muerte.

65 La ocupación estadounidense del territorio dominicano se produjo a partir del 29 de agosto de 1916 y permaneció hasta el 12 de julio de 1924.

66 Fuller, B.H., "Orden Ejecutiva No. 259 reglamentado todo lo relativo a entrada y salida de braceros al país". Santo Domingo, Gaceta Oficial, año XXXV, 26 de febrero de 1919, BNPHU, No. 2989. A partir de la aprobación de la Ley de 
en territorio dominicano si así lo deseaba; y tenía derecho a solicitar al Departamento de Agricultura una extensión de su permiso de permanencia ${ }^{67}$. Quien tuviera interés en formalizar su presencia también debía pagar un timbre a Rentas Internas, cuyo precio era variable. El empleador podía ser penalizado con RD $\$ 100$ si se negaba a cumplir con lo estipulado. Se prohibía a los capitanes de embarcaciones, a los agentes navieros $\circ$ a los representantes de empresas extranjeras presionar a los braceros y exigirles que abandonaran el país68; por lo tanto, quienes así lo decidieran, tendrían la posibilidad de permanecer en el país.

La legislación sobre migración daba escasas concesiones a los braceros no europeos. Sin embargo, en diciembre de 1919 se abrió la oportunidad de entrada de migrantes de distintas procedencias 69 . Los no caucásicos, y sus familiares, que no tuvieran permiso de la Secretaría de Agricultura, debían pagar entre US\$10 y US\$100 como máximo, dando un plazo de cuatro meses para que el migrante regularizara su situación. A la vez, se otorgaba autoridad al Secretario de Agricultura e Inmigración para suspender cualquier fallo de deportación dictada por un tribunal.

Las citadas legislaciones estaban orientadas a favorecer los intereses de la industria azucarera en la región oriental, donde existía mayor demanda de braceros extranjeros. A partir de 1920 la legislatura promovió la entrada de braceros haitianos. En la región fronteriza con Haití se disponía de tres lugares por donde se realizaría el control: Comendador, Las Lajas y Dajabón70. Con la promulgación de esa ley se favorecían los intereses de la inversión azucarera de Estados Unidos en la República Dominicana.

Inmigración de 1912 y su reglamento en 1913 a los braceros que laboraban en las unidades azucareras, se dejó que fueran estas las que solicitaran los permisos de esos inmigrantes.

67 Snowden, Thomas, "Orden Ejecutiva 431 que enmienda el artículo 87 apartado 2 de la Orden Ejecutiva 197 que se refiere a inmigración de braceros". Santo Domingo, Gaceta Oficial, año XXXVI, 27 de marzo de 1920, BNPHU, No. 3102.

68 En años posteriores a esa disposición, favorable a los intereses de la agroindustria azucarera, la misma fue reiterada por Juan Bautista Vicini Burgos cuando dirigía una administración transitoria con el fin de convocar a elecciones para elegir un presidente y poner fin a la ocupación militar. Vicini Burgos disponía de centrales azucareros. Gaceta Oficial, 17 de enero de 1923.

69 Snowden, Thomas, "Orden Ejecutiva 372 que se relaciona con la entrada en el país de inmigrantes que no sean de la raza caucásica". Santo Domingo, Gaceta Oficial, año XXXV, 24 de diciembre de 1919, BNPHU, No. 3075.

70 Snowden, Thomas, "Orden Ejecutiva 5 de la Secretaría de Agricultura e Inmigración que se relaciona con la entrada en el país de los inmigrantes de la raza de color". Santo Domingo, año XXXVI, 24 de enero de 1920, BNPHU, No. 3084. 


\section{Control y presión sobre inmigrantes}

A partir de la administración del general Rafael Trujillo Molina, iniciada en agosto de 1930, los reglamentos aplicados a los migrantes se hicieron más estrictos y restrictivos en el cobro de impuestos, a fin de incrementar la recaudación del Estado. Trujillo había prometido a las autoridades de los Estados Unidos ser fiel al pago de la deuda externa71. Para cumplir con el pago de esta deuda aumentó la presión fiscal $y$, entre los afectados, estuvieron los inmigrantes. Cabe indicar que el compromiso de pago de la deuda fue acordado pocos días después que el ciclón San Zenón destruyera la capital dominicana, creando una situación de desastre natural en el escenario de la crisis económica mundial iniciada en 1929. Ambas situaciones dejaban poco margen de superávit a la economía nacional72, y entre otros recortes dispuestos fueron afectados los presupuestos de la Secretaría de Educación y de Salud73.

En uno de sus primeros actos de gobierno, el presidente Trujillo cambió el plazo de pago de los permisos de residencia para los extranjeros radicados en el país del 1 de enero al 31 de diciembre 74 . Este cambio de fecha alteró los planes de pago de los inmigrantes antillanos británicos. La misma disposición exigió también el cobro de RD\$ 3, mediante la adquisición de un timbre en las oficinas de Rentas Internas, que debía ser colocado al dorso de la solicitud para el ingreso al país75.

La misión diplomática del Reino Unido en la República Dominicana reaccionó en varias ocasiones ante la arbitraria legislación que lesionaba los intereses de los inmigrantes antillanos británicos. En una de esas ocasiones, el diplomático inglés Wm. A. Elders se entrevistó con el inspector de inmigración Julio Sánchez para consultar sobre la detención de varios antillanos por las fuerzas policiales alegando el incumplimiento del pago de RD\$ 3 por tributos migratorios. Elders manifestó la preocupación del colectivo británico ante la represión de la fuerza pública y la

71 Trujillo, Rafael L., Discursos, mensajes y proclamas, tomo I, Editorial El Diario, Santiago, 34.

72 El ciclón, que apagó miles de vida, destruyó la capital dominicana el 3 de septiembre de 1930. El día 20 Trujillo les comunicó a las autoridades estadounidenses la negativa de aceptar una moratoria.

73 Capdevila, Lauro, La dictadura de Trujillo, Sociedad Dominicana de Bibliófilos, Santo Domingo, 2000, 54.

74 Trujillo, Rafael L., "Decreto 72 del Poder Ejecutivo estableciendo que la validez de los permisos de inmigración se contará del 1ero. de enero al 31 de diciembre, 27 de diciembre de 1930". Santo Domingo, Gaceta Oficial, BNPHU, No. 4314. Por decreto 863 de noviembre de 1927 el presidente Horacio Vásquez había establecido que el tiempo del permiso se extendiera de mayo a mayo de cada año.

75 El pago de los RD\$3 lo había establecido la administración de Horacio Vásquez en la Ley 250 del 19 de octubre de 1925. 
posibilidad de nuevas y mayores detenciones76. Entre los afectados hubo quienes fueron sentenciados al pago de multas y quienes fueron deportados del país.

A la obligación del pago del impuesto de inmigración se añadieron dos tributos adicionales: primero, el pago de la cédula personal de identidad, que implicaba erogación cada año; y segundo, el gasto por la fotografía que debía llevar el documento. Cada persona mayor de 18 años estaba obligada a portar la cedula77, sin embargo, posteriormente la edad para obtenerlo fue bajada a 16 años, lo que incrementó el número de trabajadores migrantes obligados a pagar la contribución 78 . También se prohibió a los extranjeros el acceso a los empleos públicos, con lo que se les estrechaba el mercado laboral79. Esta restricción, emitida mediante la Ley 42, fue ampliada y reforzada con la Ley 51, de 1938, la cual prohibía a las empresas privadas tener en su nómina a más de un $30 \%$ de extranjeros 80 .

Las decisiones de las autoridades en materia de inmigración se amparaban en la Convención de Extranjeros, firmada en la Habana el 20 de febrero de 1928. En este documento los países del continente acordaron el tratamiento que darían a los inmigrantes en sus respectivos territorios: establecieron las condiciones de entrada y residencia, el pago de tributos, el reconocimiento de los derechos civiles de los migrantes y la prohibición de inmiscuirse en la política interna, bajo amenaza de ser expulsados por razones de orden y seguridad pública81.

Al impuesto recaudado por la emisión de la cédula de identidad para todo inmigrante se sumó otro tributo: los trabajadores extranjeros originarios de África o de Asia, braceros o no, debían pagar RD $\$ 300$ por el permiso de entrada y RD $\$ 100$ por el permiso de permanencia en el territorio nacional; es necesario agregar que el candidato que solicitara el permiso de permanencia debía poner, al dorso de la

76 National Archives. Foreign Office, Londres, 140/17, 1929. Wm. A. Elders, Memorandum 29-5-1930 y W. H. Gallienne to Secretary of State for Foreign Affaires.

77 Trujillo, Rafael L., "Ley 247 de Cédula personal de identidad”. Colección de Leyes, Decretos y Resoluciones emanados de los Poderes Legislativo y Ejecutivo de la República. Santo Domingo, Imprenta de J. R. Vda. García, Sucesores, 1932, 271-274.

78 Congreso Nacional, "Ley 372 sobre cédula personal de identidad". Colección de Leyes, Decretos y Resoluciones emanados de los Poderes Legislativo y Ejecutivo de la República. Santo Domingo, Imprenta de J. R. Vda. García, Sucesores, 1941, 387-410.

79 Congreso Nacional, "Ley 42 del Congreso Nacional prohibiendo que ningún extranjero sea designado para desempeño de ningún cargo público". Santo Domingo, Gaceta Oficial, año LVII, 7 de enero de 1931, BNPHU, No. 4318.

80 Congreso Nacional, "Ley 51 de Dominicanización del trabajo". Santo Domingo, Gaceta Oficial, año LIX, 28 de diciembre de 1938, BNPHU, No. 5258.

81 Congreso Nacional, "Resolución 413 del Congreso Nacional que aprueba la Convención sobre la condición de los extranjeros". Santo Domingo, Gaceta Oficial, año LVIII, 3 de diciembre de 1932, BNPHU, Santo Domingo, No. 4525. 
solicitud, dos estampillas valoradas en RD \$3 cada una. Quedaban exonerados los que tenían dos años residiendo en el país o tuvieran establecimientos comerciales ${ }^{82}$. El incumplimiento de estas normas era castigado con multas de elevadas sumas que no estaban al alcance de los salarios de los obreros. Esta decisión, aplicada sólo a originarios de África o de Asia, estaba alineada con la política de blanqueamiento del régimen trujillista, que pretendía evitar la entrada de personas no caucásicas para impedir que el pueblo dominicano perdiera sus 'raíces originarias hispánicas' en varias generaciones, como expresaron algunos funcionarios artífices de la política exterior del régimen.

En ese sentido, John Simon, funcionario en el Foreign Office, percibía que en los países de Suramérica y Centro América se estaban aplicando restricciones de entrada a los súbditos británicos procedentes del Caribe, y que las autoridades dominicanas se estaban sumando a ese tipo de legislación. Así lo manifestó en una circular fechada en enero de 193283, dirigida a las representaciones del Reino Unido en Suramérica, Centroamérica y el Caribe. Con el fin de obtener un panorama más aproximado a la realidad, Simon solicitó información sobre la legislación vigente en materia inmigración y la manera como ésta afectaba a los británicos caribeños. A la vez, pidió datos sobre el número de antillanos británicos y las islas de donde procedían. También requirió que los británicos residentes en las regiones mencionadas fueran consultados para conocer sus opiniones respecto al empleo o alguna presión gubernamental que forzara la emigración de los británicos desde esos lugares. Ante situaciones adversas para los británicos en el exterior, Simon no descartó la posibilidad de repatriación a los territorios del Reino Unido de donde procedían, en caso de ser necesario.

El requerimiento de información solicitado por John Simon fue una reacción de las autoridades en el Reino Unido ante las acciones que sus pares de Suramérica, Centroamérica y el Caribe aplicaban en perjuicio de los braceros antillanos británicos. Al parecer, la decisión que tomó el gobernador de Barbados de prohibir la salida de obreros de esa isla hacia la República Dominicana respondía también a esta situación adversa. Al respecto, el Listín Diario reprodujo una comunicación aparecida en un

\footnotetext{
82 Congreso Nacional, "Ley 279 que fija los impuestos que deberán pagar todos los individuos de nacionalidad extranjera para entrar o residir en la República Dominicana". Santo Domingo, Gaceta Oficial, año LVIII, 3 de febrero de 1932, No. 4435.

83 Foreign Office, Londres, 371/15840, 1932. Circular, January 12, 1932. A 7336/4718/32.
} 
periódico de Barbados, The Barbado Avocate, donde se comentaba que dicha prohibición tenía carácter de represalia por los impuestos de inmigración y las obligaciones de pago para obtener la cédula de identidad84. Ese mismo año la administración del general Trujillo aprobó nuevas leyes impositivas: quienes quedaban gravados por nuevos impuestos eran los extranjeros que salieran del país por la vía marítima o aérea; se les exigiría obtener un certificado de vacunación, al que debía colocársele un timbre de Rentas Internas valorado en $\operatorname{RD~} \$ 585$.

Residentes de diversas nacionalidades se vieron afectados por la aplicación de las leyes de inmigración que las autoridades dominicanas emitieron a partir de 1932. En la comunidad de ciudadanos haitianos, 85 personas fueron condenadas a seis meses de prisión bajo la acusación de incumplir estas leyes ${ }^{86}$. La comunidad china del Cibao manifestó su voluntad de salir con rumbo a Venezuela por las presiones recibidas de parte de las autoridades 87 . En el colectivo de migrantes españoles, 41 personas abandonarían el país por los mismos motivos, según informó el redactor de El Listín Diario88. Con el propósito de impedir que saliera más 'gente deseada', el presidente ordenó reformar la Ley89, disponiendo la exoneración del pago de tributos a los que sumaban 20 años residiendo en el país, a las mujeres y a los mayores de 21 años 90 . Eso no fue lo suficientemente convincente para retener migrantes en territorio dominicano. Los puertorriqueños plantearon su retiro en masa después de esta reforma ${ }^{91}$.

Después de la matanza de varios miles de haitianos, en 1937, las leyes emitidas sobre migración hicieron aún más visible el concepto étnico. En la Ley 220 de 1940, que exoneraba del pago de tributos a quienes fomentaran la inmigración, quedó expresado ese interés. En el preámbulo de la ley se establecía que las personas beneficiadas con la exoneración de tributos debían ser: "personas aceptables, sanas,

84 "El Gobierno Inglés prohíbe en Barbados la emigración de braceros de color a Santo Domingo". Listín Diario, 25 de mayo de 1932.

85 Congreso Nacional, "Ley 386 que exige a toda persona que salga del país para el extranjero estar provista de un certificado de salud y vacunación". Santo Domingo, Gaceta Oficial, año LVIII, 23 de noviembre de 1932, BNPHU, No. 4522.

86 "85 haitianos fueron condenados ayer a seis meses de prisión por violación a la Ley de Inmigración”. La Información, 8 de marzo de 1932.

87 "Muchos chinos de Santiago se irán del país". Listín Diario, 25 de mayo de 1932.

88 “41 españoles más regresan a la Madre Patria por vapor 'Juan Sebastián El Cano”. Listín Diario, 25 de mayo de 1932.

89 La Opinión, abril de 1932.

90 Congreso Nacional, "Ley 338 que fija los impuestos que deberán pagar todos los individuos de nacionalidad extranjeras para entrar o residir en la República Dominicana". Santo Domingo, Gaceta Oficial, año ,14 de mayo de 1932, BNPHU, No. 4465.

91 “Desean abandonar el País muchos puertorriqueños". Listín Diario, 8 de octubre de 1932. 
vigorosas, inteligentes, laboriosas, de buenas y civilizadas costumbres, y de raza blanca"92. Asimismo, fue establecida una tarifa para el pago de tributos por parte de los extranjeros que desearan naturalizarse. Según la Ley del 4 de diciembre de 1929, ellos estaban divididos por categorías económicas indicadas en la cédula de identidad: la condición más elevada comprendía una tarifa de $\operatorname{RD} \$ 500$, que pagarían RD $\$ 1.000$, hasta la más baja de 0.50, que pagarían RD $\$ 1093$.

A los inspectores de migración se les facultaba para investigar la veracidad de las declaraciones de los inmigrantes. Estaban autorizados para examinar documentos públicos y privados, archivos de la conservaduría de hipotecas, colecturías de Rentas Internas, Oficina de Impuesto sobre la Propiedad Urbana, Oficina de la Cédula de Identidad, Notarías, Instituciones Bancarias, oficinas de sociedades o empresas comerciales, industriales, agrícolas, de transporte y de servicios. Las informaciones obtenidas se contabilizarían para el cálculo del impuesto de inmigración ${ }^{94}$. La Ley también autorizaba a nombrar un agente con amplios poderes especiales. La administración trujillista, más allá del factor económico, consideraba la condición y origen del contribuyente. Como se aprecia, la legislación en materia económica también sirvió para establecer barreras entre las comunidades y favorecer la entrada y el asentamiento de determinados grupos de inmigrantes 95 .

La política del general Trujillo respecto a la inmigración puso en práctica dos procedimientos para obtener informaciones sobre quienes ingresaban al territorio nacional. El primero consistió en el 'encuadramiento', por el cual el Estado, junto al Partido Dominicano, tenía el control de las personas. En este sistema participaban otras instituciones y organizaciones paralelas con el mismo objetivo de vigilar a los

92 Congreso Nacional, "Ley 220 exención del pago de impuesto a las personas físicas o morales autorizadas para fomentar la inmigración". Santo Domingo, Gaceta Oficial, año LXI, 28 de febrero de 1940, BNPHU, No. 5420. En esos años, el nazismo alemán tenía gran influencia en Europa y en varios países del continente americano. En el general Trujillo creó especial fascinación. Una foto de 1942 lo muestra vestido con capote, botas y quepis similares a los que usaba Hitler. La Ley aquí citada tenía un principio muy parecido al que defendía el líder alemán sobre la supremacía de la raza aria. El general dominicano, haciéndose eco del sentir de un sector de la intelectualidad, lo dispuso en el ordenamiento jurídico.

93 Congreso Nacional, "Ley 1144 que refunde en uno sólo y modifica a la vez los artículos 1 y 2 de la Ley 508, de julio 25 del 1941, sobre escala de impuestos para la obtención de la naturalización dominicana". Santo Domingo, Gaceta Oficial, año, LXVII, 10 de abril de 1946, BNPHU, No. 6424.

94 Congreso Nacional, "Ley 1235 que agrega un nuevo párrafo al artículo 1 de la Ley 496 que modificó la de Inmigración". Santo Domingo, Gaceta Oficial, año LXVII, 30 de agosto de 1946, BNPHU, No. 6495.

95 Congreso Nacional, "Ley 279 que fija los impuestos que deberán pagar todos los individuos de nacionalidad extranjera para entrar o residir en la República Dominicana". Santo Domingo, Gaceta Oficial, año LVIII, 3 de febrero de 1932, BNPHU, No. 4435. 
diferentes integrantes de la sociedad96. De ese sistema dependían otras estrategias destinadas a ejercer presión sobre los inmigrantes angloparlantes: la primera consistió en la obligación de portar placas metálicas numeradas. Dichas placas eran entregadas a cada empresa que contrataba braceros para que las asignara a cada inmigrante como forma de identificación ${ }^{97}$. Una vez que retornaran a su lugar de origen, las placas debían ser devueltas a la Dirección General de Inmigración. La segunda manera de controlar a los extranjeros consistió en el manejo de un registro de anotaciones llevado por la policía98. Sin embargo, de modo repentino esta disposición fue derogada hasta el año 1939, cuando por la Ley 95 se instauró de nuevo99. Esta ley establecía el uso obligatorio de la cédula de identidad a partir de los 16 años 100 , registro que también fue controlado por la policía ${ }^{101}$. La misma ley regulaba los lugares por donde los extranjeros debían ingresar al país 102 y autorizaba al Secretario de Interior y Policía o al Director General de Inmigración para deportar cualquier persona en caso de ser necesario 103.

El interés pecuniario por parte del Estado continuó sin dejar de lado el origen étnico. En 1943 se modificó un apartado de la Ley 95 de 1939 que, en adelante establecería el pago de RD $\$ 4$ por los permisos temporales. Los extranjeros no caucásicos pagarían RD $\$ 25$ para obtenerlo104. En una de las modificaciones al reglamento de inmigración quedó establecido que el extranjero obtendría permiso de entrar al país cuando pagara una fianza de $\operatorname{RD} \$ 75$ ejecutable en caso de no cumplir con las condiciones de admisión 105. En febrero de 1944 se jerarquizó a los

96 Cordero Michel, José, Análisis de la era de Trujillo: (Informe sobre la República Dominicana, 1959), Editora Universitaria-UASD, 1975, 39.

97 Trujillo, Rafael L., "Reglamento de Inmigración 1067". Santo Domingo, Gaceta Oficial, año LV, 19 de septiembre de 1934, BNPHU, No. 4718.

98 Congreso Nacional, "Ley 263 que pone a cargo de la Policía Nacional el registro de extranjeros (modifica el Art. 4 de la Ley 1343)". Santo Domingo, Gaceta Oficial, año LXIV, 24 de abril de 1943, BNPHU, No. 5905.

99 Congreso Nacional, "Ley 105 restablecimiento en toda su fuerza y vigor de la Ley 1343, del 10 de julio, 1937, relativa a la inscripción de extranjeros". Santo Domingo, Gaceta Oficial, año LX, 9 de mayo de 1939, BNPHU, No. 5308.

100 Congreso Nacional, "Ley 990 sobre cédula personal de identidad". Santo Domingo, Gaceta Oficial, año LXVI, 13 de septiembre de 1945, BNPHU, No. 6325.

101 Trujillo, Rafael L., “Decreto 1856 que autoriza el acceso a los Registros Centrales de la Cédula Personal de Identidad al funcionario encargado del Registro de Extranjeros". Santo Domingo, Gaceta Oficial, año LXV, 22 de abril de 1944, BNPHU, No. 6066.

102 Trujillo, Rafael L., "Decreto 3183 que reforma nuevamente el inciso a, de la sección 11, del Reglamento de Inmigración 279". Santo Domingo, Gaceta Oficial, año LXVII, 25 de enero de 1946, BNPHU, No. 6386.

103 Trujillo, Rafael L., “Decreto 3873, que agrega un acápite a la sección 13 del Reglamento de Inmigración 279". Santo Domingo, Gaceta Oficial, año LXVII, 26 de octubre de 1946, BNPHU, No. 6519.

104 Congreso Nacional, "Ley 354 que modifica un apartado del artículo 9 de la Ley de Inmigración". Santo Domingo, Gaceta Oficial, año LXIV, 10 de agosto de 1943, BNPHU, No. 5956.

105 Trujillo, Rafael L., "Decreto 1316 que modifica el Reglamento de Inmigración en lo relativo a estada temporal de extranjeros". Santo Domingo, Gaceta Oficial, año LXIV, 11 de agosto de 1943, BNPHU, No. 5957. 
extranjeros para cobrarles el impuesto relacionado con la ley de inmigración. El patrimonio personal fue el referente para establecer el monto a pagar por la renovación de los permisos de residencia106. El siguiente cuadro, que muestra los tributos puestos a los migrantes entre 1905 y 1949, permite distinguir las tasas aplicadas según la preferencia o presión estatal sobre determinados grupos étnicos:

Tributos impuestos a los migrantes entre 1905 y 1949

\begin{tabular}{|c|c|c|c|}
\hline Fecha de publicación & Ley & Descripción & Pesos RD\$ \\
\hline 17 de abril de 1905 & Ley 739 & $\begin{array}{l}\begin{array}{l}\text { Permiso de entrada para braceros } \\
\text { inmigrantes }\end{array} \\
\end{array}$ & 4 \\
\hline 26 de abril de 1905 & $\begin{array}{l}\text { Modifi- } \\
\text { cación de la } \\
\text { ley } 95\end{array}$ & $\begin{array}{l}\text { Permiso temporal de permanencia para } \\
\text { extranjeros }\end{array}$ & 4 \\
\hline 19 de octubre de 1925 & Ley 250 & Timbre para permiso de residencia & 3 \\
\hline 4 de diciembre de 1929 & Ley 1144 & Tarifa de naturalización & $\begin{array}{l}\text { entre } \\
1000 \text { y } 10\end{array}$ \\
\hline 3 de febrero de 1932 & Ley 279 & Permiso de entrada al país & 300 \\
\hline 3 de febrero de 1932 & Ley 279 & Permiso de permanencia en el país & 100 \\
\hline 3 de febrero de 1932 & Ley 279 & Timbre para el permiso de permanencia & 3 \\
\hline 23 de noviembre de 1932 & Ley 386 & $\begin{array}{l}\text { Timbre para el certificado de vacunación al } \\
\text { salir del país }\end{array}$ & 5 \\
\hline 15 de marzo de 1933 & Ley 463 & Timbre de rentas internas para cédula & 2 \\
\hline 4 de noviembre de 1933 & Ley 587 & $\begin{array}{l}\text { Autorización a extranjeros para fijar } \\
\text { residencia }\end{array}$ & 10 \\
\hline 18 de agosto de 1934 & Ley 739 & Permiso de permanencia para braceros & 4 \\
\hline 18 de agosto de 1934 & Ley 739 & $\begin{array}{l}\text { Permiso de entrada para braceros } \\
\text { contratados }\end{array}$ & 3 \\
\hline 18 de agosto de 1934 & Ley 739 & $\begin{array}{l}\text { Permiso de permanencia para braceros } \\
\text { contratados }\end{array}$ & 3 \\
\hline 18 de agosto de 1934 & Ley 739 & $\begin{array}{l}\text { Permiso de permanencia para braceros por } \\
15 \text { días después de la zafra }\end{array}$ & 2 \\
\hline 11 de marzo de 1939 & Ley 85 & $\begin{array}{l}\text { Permiso de entrada y permanencia para } \\
\text { inmigrantes semitas }\end{array}$ & 3 \\
\hline 10 de agosto de 1943 & Ley 354 & $\begin{array}{l}\text { Permiso temporal de permanencia para } \\
\text { inmigrantes no caucásicos }\end{array}$ & 25 \\
\hline 11 de agosto de 1943 & $\begin{array}{l}\text { Decreto } \\
1316\end{array}$ & $\begin{array}{l}\text { Permiso de ingreso al país para inmigrantes } \\
\text { sin condiciones de admisión }\end{array}$ & 75 \\
\hline
\end{tabular}

106 Congreso Nacional, "Ley 496, que modifica el apartado e, del artículo 9, de la Ley de Inmigración, estableciendo una escala para el pago de la renovación de los permisos de residencia". Santo Domingo, Gaceta Oficial, año LXV, 10 de febrero de 1944, BNPHU, No. 6032. 


\begin{tabular}{|c|c|c|c|}
\hline 10 de febrero de 1944 & Ley 496 & $\begin{array}{l}\text { Renovación del permiso de residencia para } \\
\text { inmigrantes con patrimonio mayor que RD\$ } \\
200.000 \text { y rentas mayores que RD\$2.500 }\end{array}$ & 100 \\
\hline 10 de febrero de 1944 & Ley 496 & $\begin{array}{l}\text { Renovación del permiso de residencia para } \\
\text { inmigrantes con patrimonio mayor que RD\$ } \\
200.000 \text { y rentas comprendidas entre RD\$ } \\
1.000 \text { a RD\$ } 2.500\end{array}$ & 75 \\
\hline 10 de febrero de 1944 & Ley 496 & $\begin{array}{l}\text { Renovación del permiso de residencia para } \\
\text { inmigrantes con patrimonio entre RD\$ } \\
50.000 \text { y RD\$ } 200.000 \text { y rentas comprendidas } \\
\text { entre RD\$ } 1.000 \text { y RD } \$ 2.500\end{array}$ & 50 \\
\hline 10 de febrero de 1944 & Ley 496 & $\begin{array}{l}\text { Renovación del permiso de residencia para } \\
\text { inmigrantes con patrimonio mayor que RD\$ } \\
25.000 \text { y rentas comprendidas entre RD\$500 } \\
\text { y RD\$ } 1.000\end{array}$ & 25 \\
\hline 10 de febrero de 1944 & Ley 496 & $\begin{array}{l}\text { Renovación del permiso de residencia para } \\
\text { inmigrantes con patrimonio mayor que RD\$ } \\
10.000 \text { y rentas comprendidas entre RD\$ } 250 \\
\text { y RD\$ } 500\end{array}$ & 15 \\
\hline 10 de febrero de 1944 & Ley 496 & $\begin{array}{l}\text { Renovación del permiso de residencia para } \\
\text { inmigrantes con un patrimonio mayor que } \\
\text { RD\$ } 2.500 \text { y rentas comprendidas entre RD\$ } \\
150 \text { y RD\$ } 250\end{array}$ & 7.5 \\
\hline 10 de febrero de 1944 & Ley 496 & $\begin{array}{l}\text { Renovación del permiso de residencia para } \\
\text { trabajadores de empresas agrícolas e } \\
\text { industriales }\end{array}$ & 6 \\
\hline 10 de febrero de 1944 & Ley 496 & $\begin{array}{l}\text { Renovación del permiso de residencia para } \\
\text { empleados con renta mensual comprendida } \\
\text { entre RD\$50 y RD\$ } 150\end{array}$ & 4 \\
\hline 10 de febrero de 1944 & Ley 496 & $\begin{array}{l}\text { Renovación del permiso de residencia para } \\
\text { todo aquel no comprendido en las categorías } \\
\text { anteriores }\end{array}$ & 1 \\
\hline 8 de noviembre de 1948 & Ley 1831 & $\begin{array}{l}\text { Permiso de reentrada a pagarse antes de } \\
\text { salir }\end{array}$ & 10 \\
\hline 28 de diciembre de 1948 & Ley 48 & $\begin{array}{l}\text { Permiso de entrada para hombres mayores } \\
\text { de } 16 \text { años y mujeres mayores de } 18 \text { años } \\
\text { que carecen de nacionalidad por haberla } \\
\text { perdido }\end{array}$ & 500 \\
\hline 28 de diciembre de 1948 & Ley 48 & $\begin{array}{l}\text { Permiso de permanencia para hombres } \\
\text { mayores de } 16 \text { años y mujeres mayores de } 18 \\
\text { años que carecen de nacionalidad por } \\
\text { haberla perdido }\end{array}$ & 6 \\
\hline 28 de diciembre de 1948 & Ley 48 & $\begin{array}{l}\text { Permiso de entrada o residencia para } \\
\text { inmigrantes asiáticos o africanos }\end{array}$ & 500 \\
\hline 12 de abril de 1949 & Ley 1973 & $\begin{array}{l}\text { Servicio del inspector de inmigración en } \\
\text { horario determinado }\end{array}$ & 3 \\
\hline
\end{tabular}

Fuente: Elaborado a partir de las publicaciones de la Gaceta Oficial en la fecha indicada 
El siguiente cuadro muestra la escala de la recaudación fiscal por concepto de la emisión de timbres que debían adquirir los extranjeros para efectuar trámites migratorios.

\begin{tabular}{lll}
\hline Fecha & Número & de \\
& sellos & valor en RD\$ \\
\hline 8 de septiembre de 1934 & 20.000 & 4 \\
\hline 8 de septiembre de 1934 & 10.000 & 2 \\
\hline 27 de enero de 1937 & 10.000 & 2 \\
\hline 27 de enero de 1937 & 10.000 & 4 \\
\hline 4 de diciembre de 1937 & 25.000 & 5 \\
\hline 4 de diciembre de 1937 & 25.000 & 4 \\
\hline 6 de marzo de 1940 & 4.000 & 10 \\
\hline 26 de febrero de 1944 & 30.000 & 4 \\
\hline 26 de febrero de 1944 & 10.000 & 1 \\
\hline 6 de marzo de 1948 & 25.000 & 4 \\
\hline
\end{tabular}

Fuente: Elaborado a partir de las publicaciones de la Gaceta Oficial en la fecha indicada

Respecto a la inmigración femenina, la política migratoria liberaba del pago de entrada y permanencia a las mujeres casadas. También otorgaba esa gracia a quienes residieran en el país por cinco años como mínimo y hubieran contraído matrimonio con nacionales. De igual modo, se beneficiaban las que residieran en este territorio durante diez años y tuvieran hijos dominicanos 107. Respecto a la naturalización, cuando desearan hacerlo deberían tributar $\operatorname{RD} \$ 100$, mientras que los hombres pagarían RD $\$ 200108$. La renovación del permiso de residencia de los matrimonios con bienes comunes se cobraría sobre el valor total de los bienes, y para la renovación del permiso de residencia de la esposa no se tomaría en consideración el valor de los bienes comunes 109.

107 Congreso Nacional, "Ley de inmigración 739". Santo Domingo, Gaceta Oficial, año LV, 18 de agosto de 1934, No. 4710.

108 Congreso Nacional, "Ley 1083 de naturalización condicional de inmigrantes". Santo Domingo, Gaceta Oficial, año LVII, 4 de abril de 1936, BNPHU, No. 4892.

109 Congreso Nacional, “Ley 1475 que agrega un párrafo al apartado e, del artículo 8, de la Ley de Inmigración 95”. Santo Domingo, Gaceta Oficial, año LXVIII, 16 de julio de 1947, No. 6661. 


\section{Conclusión}

El fomento de la migración en la Republica Dominicana, entre 1870 y 1950 , surge con la finalidad de poblar el territorio nacional por razones de seguridad e impulsar el progreso del país con el aporte de los ciudadanos europeos que llegaban hacia América en busca de tierras para trabajar y subsistir. En un primer momento, la política migratoria dominicana del siglo XIX sostiene el objetivo de atraer ciudadanos europeos que decidan radicar en estas tierras, y en favor de ellos impulsa proyectos de desarrollo para ofrecer mejor calidad de vida a los potenciales migrantes. Sin embargo, en un segundo momento durante el siglo XX, este proyecto fracasa y debe asumir el arribo de numerosos trabajadores afrodescendientes, procedentes de otras islas del Caribe, que son contratados para laborar temporalmente como obreros y braceros en la creciente industria azucarera moderna.

Ante el nuevo escenario, la política migratoria dominicana pasa a ejercer prácticas de vigilancia y presión por medio de la imposición de tributos y otros sistemas de control sobre los trabajadores de origen antillano británico y haitiano. Al paso del tiempo, el tinte étnico en el ejercicio de la política migratoria dominicana persiste y es motivo de debate actual.

Fecha de recepción: 30/11/19 


\section{Referencias Bibliográficas}

Capdevila, Lauro, La dictadura de Trujillo, Sociedad Dominicana de Bibliófilos, Santo Domingo, 2000.

Cayuela, José G. (coord.), Un Siglo de España: Centenario 1898-1998, Universidad de Castilla-La Mancha/Cortes de Castilla-La Mancha, Cuenca, 1998.

Josef Opatrný (coord.), Migraciones en el Caribe hispano, Editorial Carolinum, 2012.

Colección de Leyes, Decretos, y Resoluciones emanadas de los poderes Legislativo y ejecutivo de la República Dominicana, tomo 2, Imprenta del Listín Diario, Santo Domingo, 1927.

Colección de Leyes, Decretos y Resoluciones emanadas de los poderes Legislativo y Ejecutivo de la República Dominicana, tomo 4, Imprenta del Listín Diario, Santo Domingo, 1927.

Colección de Leyes, Decretos y Resoluciones emanadas de los poderes Legislativo y Ejecutivo de la República Dominicana, tomo 5, Imprenta Listín Diario, Santo Domingo, 1927.

Colección de Leyes, Decretos y Resoluciones emanados de los poderes Legislativo y Ejecutivo de la República Dominicana, tomo 6, Imprenta del Listín Diario, Santo Domingo, 1928.

Colección de Leyes, Decretos y Resoluciones de los poderes, tomo 7, Imprenta Listín Diario, Santo Domingo, 1929.

Colección de Leyes, Decretos y Resoluciones Emanados de los Poderes Ejecutivo y Legislativo de la República Dominicana, tomo 9, Imprenta del Listín Diario, Santo Domingo, 1929.

Colección de Leyes, Decretos y Resoluciones emanados de los poderes Legislativo y Ejecutivo de la República Dominicana, tomo 11, Imprenta del Listín Diario, Santo Domingo, 1928.

Colección de Leyes, Decretos y Resoluciones emanados de los poderes Legislativo y Ejecutivo, tomo 12, Imprenta del Listín Diario, Santo Domingo, 1929.

Colección de Leyes, Decretos y Resoluciones Emanados de los Poderes Legislativo y Ejecutivo de la República Dominicana, tomo 13, Imprenta del Listín Diario, Santo Domingo, 1929.

Colección de Leyes, Decretos y Resoluciones emanados de los Poderes Legislativo y Ejecutivo de la República, Imprenta de J. R. Vda. García, Sucesores, Santo Domingo, 1941.

Cordero Michel, José, Análisis de la era de Trujillo: (Informe sobre la República Dominicana, 1959), Editora Universitaria-UASD, 1975. 
Guerra, Ramiro, Azúcar y población en las Antillas, Editorial de Ciencias Sociales, La Habana, 1976.

Informe de la Comisión de investigación de los E. U. A. en Santo Domingo en 1871, Prefacio y notas de E. Rodríguez Demorizi, Editora Montalvo, Ciudad Trujillo, 1960 (Academia Dominicana de la Historia IX).

Jarvis Luis, Rafael, "Ulises Heureaux: la coyuntura política de 1888 a través de sus correspondencias", en País Cultural. Ministerio de Cultura. Año IX, Número 16, Octubre de 2014.

Mintz, Sydney W., "La resistencia cultural y la fuerza de trabajo en el Caribe", El Caribe Contemporáneo, No. 6., Facultad de Ciencias Políticas y Sociales, UNAM y Centro de Estudios Latinoamericanos, México.

Naranjo Orovio, Consuelo y García Armando, "Inmigraciones e 'higiene racial' en Cuba, 1900-1940", en Cayuela Fernández, José G. (coord.), Un siglo de España: Centenario, 1898-1998. (En colaboración con la Universidad de La Habana), Ed. Universidad de Castilla-La Mancha, Cuenca, 1998, 437-450.

Naranjo Orovio, Consuelo y Petinnà, Vanni, "Un nuevo orden: inmigración y prejuicios sociales en Cuba, 1900-1930", en Pablo Yankelevich (coord.), La nación y extranjería en América Latina. Normas y prácticas de exclusión en las políticas migratorias, UNAM-ENAH, México, 2009, 95-145.

Naranjo Orovio, Consuelo, "Debates en torno a la inmigración en Cuba, 1800-1930", en Opatrný, Josef (coord.), Migraciones en el Caribe Hispano, Ibero-Americana Pragensia, Supplementum, Universidad Carolina, Praga, 2012, 25-39.

Naranjo Orovio, Consuelo, "Immigration, Race and Nation in Cuba in the Second Half of the XIX Century", Ibero-Amerikanisches Archiv (Monográfico: Race, Society and Culture in Afro-Latin America) vol. 24, núms. 3-4: 1-00, Berlin, 1998, 303-326.

Naranjo Orovio, Consuelo. "Inmigración española e imaginario nacional en Cuba, 19001920", Mauricio Font and Alfonso Quiroz (eds.), The Cuban Republic and Jose Marti: Reception and Use of a National Symbol, Lexington Books, Lanham, Maryland, 2006, 155-170.

Naranjo Orovio, Consuelo, Del campo a la bodega. Recuerdos de gallegos en Cuba, siglo XX, Ediciós do Castro, A Coruña, 1988.

Naranjo Orovio, Consuelo, Las migraciones de España a Iberoamérica desde la Independencia, CSIC, Madrid, 2010.

Puig-Samper, Miguel Ángel, Orrego, Francisco, Ruiz, Rosaura Ruiz y Uribe, J. Alfredo (eds.), Yammerschuner. Darwin y la darwinización en Europa y América Latina, Ed. Doce Calles-UNAM-DIBAM, Madrid-México-Santiago de Chile, 2014.

Ruiz, Rosaura, Puig-Samper, Miguel Ángel y Zamudio, Graciela (eds.), Darwinismo, Biología y Sociedad, UNAM/Doce Calles, México/Madrid, 2013. 
Tolentino Rojas, Historia de la división territorial, 2da. Edición, Sociedad Dominicana de Bibliófilos, Santo Domingo, 1993.

Trujillo, Rafael L., Discursos, mensajes y proclamas, tomo I. Editorial El Diario, Santiago.

Watts, David, Las Indias Occidentales. Modalidades de desarrollo, cultura y cambio medioambiental desde 1492, Alianza Editorial, Madrid, 1992.

Weinberg, Gregorio, La ciencia y la idea de progreso en América Latina, 1860-1930. 2 da., Fondo de Cultura, México, 1998.

Yankelevich, Pablo (coord.), La nación y extranjería en América Latina. Normas y prácticas de exclusión en las políticas migratorias, UNAM-ENAH, México, 2009. 